\title{
A consistent molecular hydrogen isotope chemistry scheme based on an independent bond approximation
}

\author{
G. Pieterse, M. C. Krol, and T. Röckmann \\ Institute for Marine and Atmospheric Research Utrecht, Utrecht, The Netherlands \\ Received: 2 December 2008 - Published in Atmos. Chem. Phys. Discuss.: 3 March 2009 \\ Revised: 1 October 2009 - Accepted: 18 October 2009 - Published: 9 November 2009
}

\begin{abstract}
The isotopic composition of molecular hydrogen $\left(\mathrm{H}_{2}\right)$ produced by photochemical oxidation of methane $\left(\mathrm{CH}_{4}\right)$ and Volatile Organic Compounds (VOCs) is a key quantity in the global isotope budget of $\left(\mathrm{H}_{2}\right)$. The many individual reaction steps involved complicate its investigation. Here we present a simplified structure-activity approach to assign isotope effects to the individual elementary reaction steps in the oxidation sequence of $\mathrm{CH}_{4}$ and some other VOCs. The approach builds on and extends the work by Gerst and Quay (2001) and Feilberg et al. (2007b). The description is generalized and allows the application, in principle, also to other compounds. The idea is that the $\mathrm{C}-\mathrm{H}$ and $\mathrm{C}$-D bonds - seen as reactive sites - have similar relative reaction probabilities in isotopically substituted, but otherwise identical molecules. The limitations of this approach are discussed for the reaction $\mathrm{CH}_{4}+\mathrm{Cl}$. The same approach is applied to VOCs, which are important precursors of $\mathrm{H}_{2}$ that need to be included into models. Unfortunately, quantitative information on VOC isotope effects and source isotope signatures is very limited and the isotope scheme at this time is limited to a strongly parameterized statistical approach, which neglects kinetic isotope effects. Using these concepts we implement a full hydrogen isotope scheme in a chemical box model and carry out a sensitivity study to identify those reaction steps and conditions that are most critical for the isotope composition of the final $\mathrm{H}_{2}$ product. The reaction scheme is directly applicable in global chemistry models, which can thus include the isotope pathway of $\mathrm{H}_{2}$ produced from $\mathrm{CH}_{4}$ and VOCs in a consistent way.
\end{abstract}

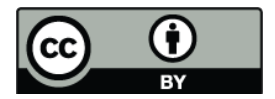

Correspondence to: T. Röckmann (t.roeckmann@uu.nl)

\section{Introduction}

Molecular hydrogen $\mathrm{H}_{2}$ is an attractive candidate as future energy carrier because combustion of $\mathrm{H}_{2}$ produces $\mathrm{H}_{2} \mathrm{O}$ only. In addition to saving the $\mathrm{CO}_{2}$ emissions (if the $\mathrm{H}_{2}$ is formed from carbon-free energy sources), also the massive energyrelated emissions of other compounds like carbon monoxide, nitrogen oxides and soot could be drastically reduced, leading to improvements in air quality (Schultz et al., 2003). Nevertheless, unavoidable leakage in the production, distribution, storage and consumption of $\mathrm{H}_{2}$ could drastically alter the mixing ratio of $\mathrm{H}_{2}$ in the atmosphere. Although it is not a greenhouse gas itself, $\mathrm{H}_{2}$ affects the atmospheric lifetime of the greenhouse gas methane and many other species via its reaction with the hydroxyl $(\mathrm{OH})$ radical (Schultz et al., 2003). In addition, $\mathrm{H}_{2}$ is an important source for stratospheric water vapor, which provides the substrate for polar stratospheric clouds that play a key role in the formation of the stratospheric polar ozone hole. Therefore, increasing levels of $\mathrm{H}_{2}$ in the atmosphere will counteract the predicted recovery of the ozone hole (Tromp et al., 2003; Warwick et al., 2004; Feck et al., 2008). For those reasons, the prospect of a potential future economy based on the energy carrier hydrogen $\left(\mathrm{H}_{2}\right)$ has recently invigorated the interest in the atmospheric budget of $\mathrm{H}_{2}$. It seems adequate to investigate and understand its atmospheric cycle in more detail before a potentially drastic anthropogenic change take place. The main sources of $\mathrm{H}_{2}$ are combustion processes (fossil fuel combustion and biomass burning) and atmospheric oxidation sources (from $\mathrm{CH}_{4}$ and VOCs), with smaller contributions from the oceans and terrestrial nitrogen fixation. $\mathrm{H}_{2}$ is removed from the atmosphere by deposition to the soil and oxidation by $\mathrm{OH}$. However, the quantitative estimates of the respective source and sink strengths are highly uncertain (Novelli et al., 1999) and should be improved to enable more reliable predictions of the effect of a hydrogen economy.

Published by Copernicus Publications on behalf of the European Geosciences Union. 
A useful method to further constrain the strengths of the individual production and destruction processes of $\mathrm{H}_{2}$ is the investigation of its stable isotope budget. The ultimate goal is to incorporate a realistic representation of the isotope signatures for all sources and sinks into global models. An important step was recently realized by Price et al. (2007), who presented the first global hydrogen isotope model. One result from this model study was that the global average isotope signature of photochemically produced $\mathrm{H}_{2}$ must be $+162_{-57}^{+57} \%$ in order to close the isotope budget with the parameters used there. However, at the same time, this is a gross simplification, since photochemical production occurs via many pathways and from numerous source molecules, such as methane $\left(\mathrm{CH}_{4}\right)$ and many other Volatile Organic Compounds (VOCs) like isoprene or methanol. Different isotope signatures are expected due to the different isotope content of the various source molecules and kinetic and branching isotope effects in the individual steps of the reaction chains.

In the case of $\mathrm{CH}_{4}$ oxidation, the largest $\mathrm{H}_{2}$ source, those isotope effects were discussed for the first time in the study of Gerst and Quay (2001). Building on this work, recent studies have attempted to investigate the overall fractionation in the oxidation chain from $\mathrm{CH}_{4}$ to $\mathrm{H}_{2}$ (Rahn et al., 2003; Röckmann et al., 2003; Rhee et al., 2006b,a, 2008), using measurements in the stratosphere where $\mathrm{CH}_{4}$ oxidation is the only relevant source of $\mathrm{H}_{2}$ and can be studied without interference from other sources. In parallel, the isotope effects in some of the individual reaction steps have been investigated (Feilberg et al., 2004, 2005, 2007a,b; Rhee et al., 2008). The isotope fractionation in the initial atomic hydrogen $\mathrm{H}$ and atomic deuterium D abstraction step is well known (Cantrell et al., 1990; Saueressig et al., 1996, 2001). Mar et al. (2007) studied in detail the deuterium content in stratospheric $\mathrm{H}_{2}$, using a chemistry model for the stratosphere. Another recent study (Zahn et al., 2006) modeled the full isotope chemistry of the $\mathrm{CH}_{4}$ oxidation chain, but $\mathrm{H}_{2}$ was not considered.

The present paper reanalyzes the isotope effects in the photochemical production of $\mathrm{H}_{2}$ with the goal of deriving flexible and consistent isotope reaction schemes that can be incorporated into models even in the absence of a full knowledge of all relevant isotope effects. Structure-activity analysis provides the basis to assign relative or absolute reaction probabilities to unknown reactions based on the chemical structure of the reactants and known reaction rates for similar molecules. In fact, Gerst and Quay (2001) and following papers in principle already applied this theory to investigate the isotope effects involved in the different steps of the $\mathrm{CH}_{4}$ oxidation chain. Here, we provide a general and formal approach and present an in-depth analysis of the photochemical production of $\mathrm{H}_{2}$ from $\mathrm{CH}_{4}$ (Sect. 2) and extend it to other molecules (Sect. 3). In addition, we implement the full hydrogen isotope chemistry in a chemical box model and carry out a sensitivity study to identify those reaction steps that are most critical for the isotope composition of the final $\mathrm{H}_{2}$ prod- uct (Sect. 4). Available data are used to derive parameterizations for missing kinetic isotope effects and branching ratios and data that may become available in the future can be easily implemented to assess their effect directly in the model. This condensed reaction scheme is suitable for incorporation into global chemistry models, which can thus include the isotope pathway of $\mathrm{H}_{2}$ produced from $\mathrm{CH}_{4}$ in a consistent and fundamental way. First results from the implementation in the TM5 model will be presented in a separate paper.

\section{Methane oxidation}

This section starts with the elementary chemistry equations for the oxidation of methane to $\mathrm{H}_{2}$ and will focus on developing a scheme for the stratosphere as well as the troposphere. The oxidation of atmospheric $\mathrm{CH}_{4}$ is based on the complete description by Ravishankara (1988) shown in Fig. 1. Tables A1 to A4 in Appendix A summarize the composing reactions. All rate constants are from Sander et al. (2006) unless stated otherwise. As the abundance of deuterium (D) atoms is much lower than that of hydrogen $(\mathrm{H})$ atoms $\left(\mathrm{D} / \mathrm{H}=1.56 \times 10^{-4}\right)$ and due to the fact that most surface sources of methane as well as hydrogen are depleted in heavier stable isotopologues (Levin et al., 1993; Rahn et al., 2002b, 2003; Rhee et al., 2006b; Price et al., 2007), we limit our analysis to isotopologues that contain either one deuterium atom or none at all.

There are three processes that have to be taken into account in deriving any isotope chemistry scheme. First, as a general rule (but not without exceptions) the heavier isotopologues are removed at a lower rate than the lighter isotopologues (e.g. Brenninkmeijer et al., 2003). This is called the Kinetic Isotope Effect (KIE). This effect causes an isotopic depletion in the product species. Second, the isotopic composition is measured in $\delta \mathrm{D}\left(\mathrm{H}_{2}\right)$ units as the ratio of $\mathrm{D}$ to $\mathrm{H}$ atoms, whereas chemical kinetics equations are usually calculated on the basis of molecules. The simple fact that the number of $\mathrm{H}$ in a chemical species is reduced in the oxidation chain (e.g. in the oxidation process of $\mathrm{CH}_{4}$ to $\mathrm{CH}_{2} \mathrm{O}$ and $\mathrm{H}_{2}$ two hydrogens are lost), means that the ratio $\mathrm{D}$ to $\mathrm{H}$ atoms is larger than that of $\mathrm{D}$ and $\mathrm{H}$ substituted product molecules, when compared to the initial molecule. We will call this effect the molecular isotopic enrichment (MIE), which is actually a counting effect. Finally, there is also a probability that somewhere along the deuterated oxidation chain a $\mathrm{D}$ atom will be removed. In such a scenario less deuterated molecular hydrogen will be formed than in a, less realistic, scenario where deuterium is fully conserved along the deuterated oxidation chain. We will call the competition of $\mathrm{H}$ abstraction versus D abstraction Isotopic Branching (IB). Only the KIE and the IB are chemical isotope effects, whereas the MIE is basically a counting issue. Nevertheless, it often causes confusion, which is why we have explicitly included it in this overview. Figure 2, shows the isotope chemistry scheme that 


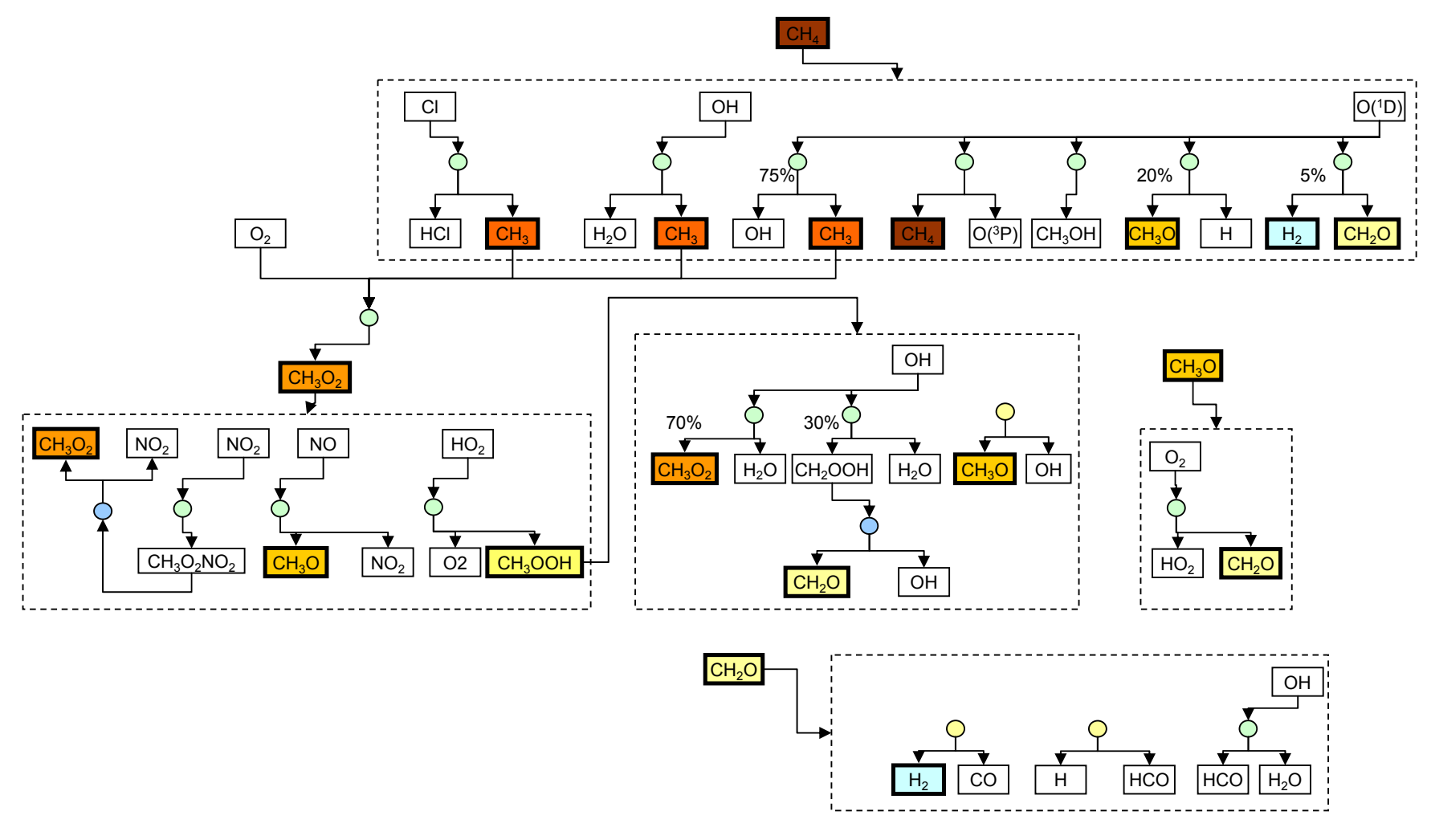

Fig. 1. Full methane oxidation scheme.

we will elucidate in the following sections. For clarity, only the reservoir species relevant to the final isotopic composition of $\mathrm{H}_{2}$ are shown here.

In principle, it is possible to perform molecular kinetics calculations to derive the reaction rates for such interactions. However, isotope effects are small and depending on the chosen model that describes the molecular interactions, such calculations often yield very different reaction rates. Therefore, we use a simplified approach and test its effectiveness in describing the involved isotope effects. Generally, the incoming radical molecules will show a certain interaction preference for the different functional groups present in a certain target molecule. Recent studies by McGillen et al. (2006b,a, 2007) show that a single topological descriptor can be used to estimate the reaction rates of large sets of different VOCs. The Structure-Activity Relationship (SAR), later renamed to Structure-Reactivity Relationship (SRR), analysis described by Atkinson (1986, 1987); Kwok and Atkinson (1995) has also proved to be a very effective method for predicting the reaction rates of VOCs. A simplified statistical approach similar to these methods is therefore used to derive expressions for the KIE's and IB ratios for all steps in this scheme. Like the method introduced by Feilberg et al. (2007a), it assumes independence of the stability of the remaining bonds of a certain chemical species upon substitution of one of the hydrogen-atoms by a deuteron. Here, a rigorous derivation is made for the whole methane oxidation chain as well as the oxidation chain of some major volatile organic species. The general concept is presented in the following subsection for the simple example of the $\mathrm{CH}_{4}+\mathrm{OH}$ reaction. This is a good illustration, because the formal approach returns a result that is easily understandable (and does itself not require the formal treatment). The derivation of the more complicated expressions for the other reaction steps is deferred to Appendix B.

\section{$2.1 \mathrm{CH}_{4}+\mathrm{OH}$ reaction}

A useful illustration for the derivation of isotope effects using the independent bond approximation is the Venn diagram (Venn, 1880), which is shown in Fig. 3 for the concurrent oxidation of $\mathrm{CH}_{4}$ and $\mathrm{CH}_{3} \mathrm{D}$ by the hydroxyl radical $(\mathrm{OH})$.

This diagram represents the different possibilities for the extraction of hydrogen or deuterium atoms from methane (the four $\mathrm{C}-\mathrm{H}$ bonds on the left side) and deuterated methane (from the three $\mathrm{C}-\mathrm{H}$ bonds and one C-D bond on the right side). The KIE for this reaction can be expressed as:

$\mathrm{KIE}_{\mathrm{CH}_{3} \mathrm{D}+\mathrm{OH}} \equiv \frac{P\left(\mathrm{CH}_{4}\right)}{P\left(\mathrm{CH}_{3} \mathrm{D}\right)}$,

i.e. as the ratio between the probability to abstract a $\mathrm{H}$ atom from the methane molecule to the probability to abstract 


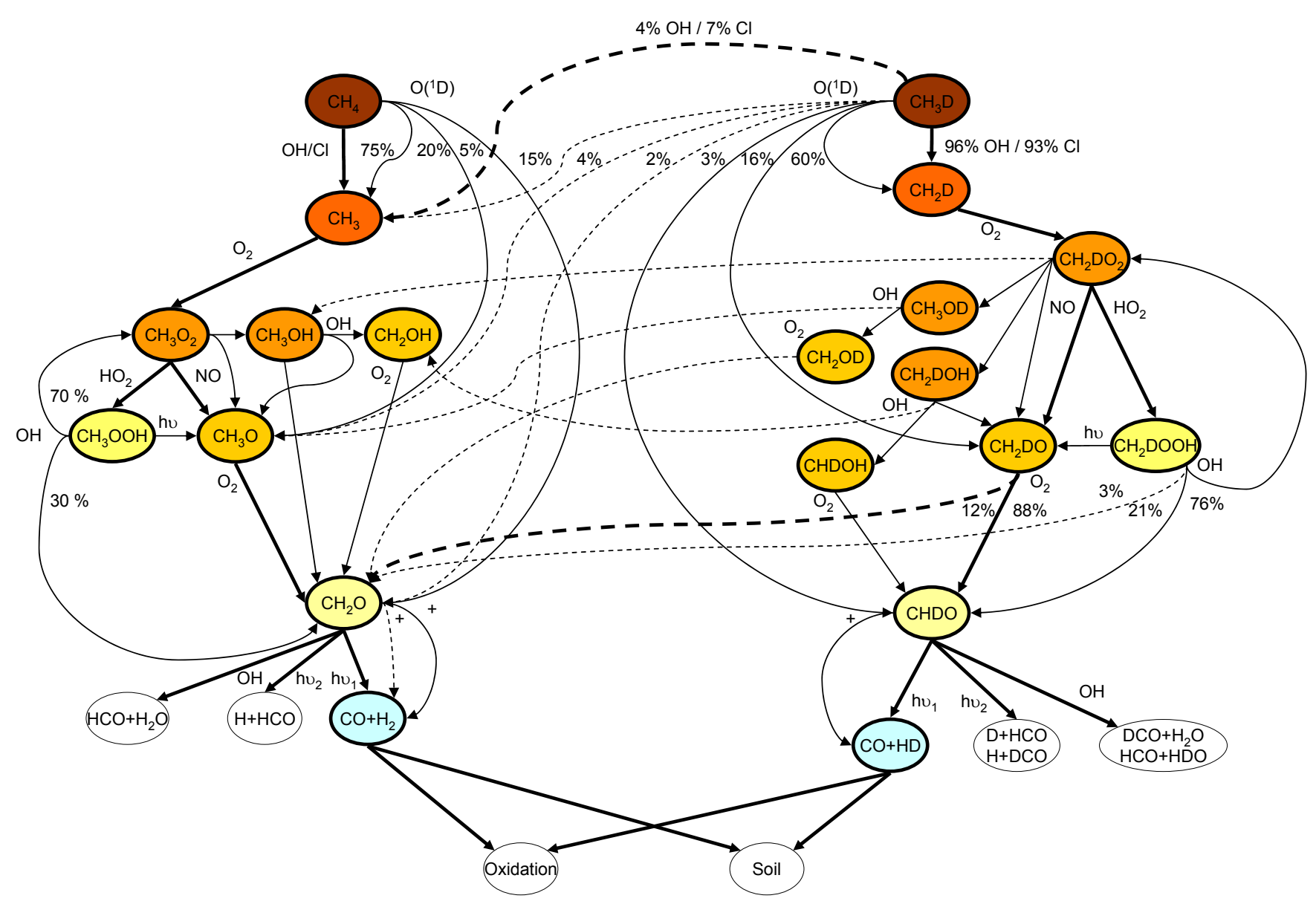

Fig. 2. Considered methane isotope oxidation scheme.

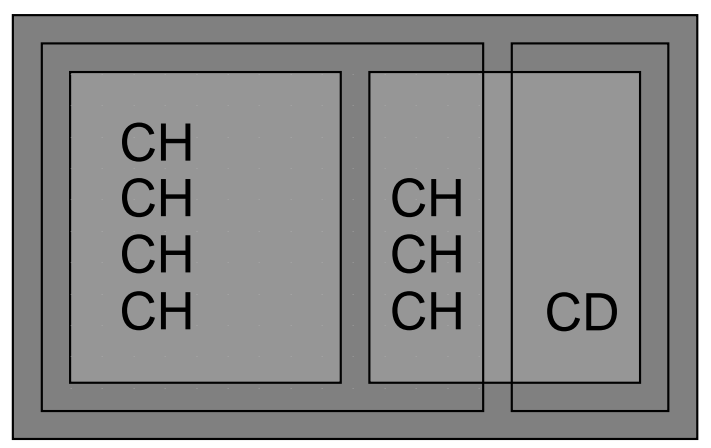

Fig. 3. Venn diagram for $\mathrm{CH}_{4}+\mathrm{OH}$ reaction.

either a $\mathrm{H}$ or $\mathrm{D}$ atom from the deuterated methane molecule. By definition:

$P\left(\mathrm{CH}_{4}\right)+P\left(\mathrm{CH}_{3} \mathrm{D}\right) \equiv 1$.

One can also look at the ensemble probability to abstract a hydrogen atom, $P(\mathrm{CH})$ and the ensemble probability to ab- stract a deuterium atom, $P(\mathrm{CD})$. It is straightforward to see that:

$P(\mathrm{CH})+P(\mathrm{CD}) \equiv 1$.

In principle, these expressions form the basis for calculating the KIE and IB ratios for the methane-hydroxyl reaction but do not enable one to calculate these quantities explicitly. The conditional probability for a certain event $A$ to happen provided that event $B$ has already happened is $P(A \mid B) \equiv \frac{P(A \cap B)}{P(B)}$. Thus the conditional probability that a deuterium atom is abstracted provided that it is abstracted from a deuterated methane molecule is:

$P\left(\mathrm{CD} \mid \mathrm{CH}_{3} \mathrm{D}\right)=\frac{P\left(\mathrm{CD} \cap \mathrm{CH}_{3} \mathrm{D}\right)}{P\left(\mathrm{CH}_{3} \mathrm{D}\right)}=\frac{P(\mathrm{CD})}{P\left(\mathrm{CH}_{3} \mathrm{D}\right)}$.

The key assumption in our approach is that the probability of abstracting a $\mathrm{H}$ atom from a compound is independent of the presence of a heavy isotope at another location in this compound, i.e., that secondary isotope effects are negligible. Therefore, the probability of abstracting an atom from a methane or deuterated methane molecule, provided that a 
hydrogen atom is abstracted from a C-H bond, scales linearly with the number of hydrogen atoms in the molecule and:

$P\left(\mathrm{CH}_{4} \mid \mathrm{CH}\right) \cong \frac{4}{3} P\left(\mathrm{CH}_{3} \mathrm{D} \mid \mathrm{CH}\right)$.

Thus, our approach neglects that in reality this probability can, and very often will be affected by the presence of the deuterium atom in the deuterated methane molecule. Equation (5) can also be written as:

$$
\frac{P\left(\mathrm{CH}_{4} \cap \mathrm{CH}\right)}{P(\mathrm{CH})} \cong \frac{4}{3} \frac{P\left(\mathrm{CH}_{3} \mathrm{D} \cap \mathrm{CH}\right)}{P(\mathrm{CH})} \text {. }
$$

Because $P(\mathrm{CH})$ cancels out, the left-hand side of this expression is equal to $P\left(\mathrm{CH}_{4}\right)$. The expression on the right-hand side can be written as $P(\mathrm{CH})-P\left(\mathrm{CH}_{4}\right)$. After rearranging the resulting expression we find:

$$
\frac{P(\mathrm{CH})}{P\left(\mathrm{CH}_{4}\right)} \cong \frac{7}{4} \text {. }
$$

Most of the equations up to now can be derived without the formal equations from the assumption that the abstraction probability of a $\mathrm{H}$ atom does not depend on the isotopic substitution of the $\mathrm{CH}_{4}$ molecule. Equation (1) can be rewritten in the form:

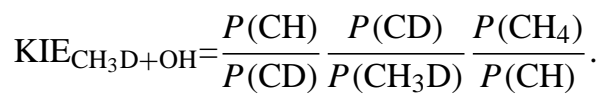

Equation (7) provides an explicit value for the last ratio on the right-hand side. The two remaining ratios can be calculated by introducing a ratio $\eta_{\mathrm{CH}_{4}+\mathrm{OH}}^{\mathrm{CH}}$, i.e., the preference of abstraction from hydrogen atoms over the abstraction from deuterium atoms:

$$
\frac{P(\mathrm{CD})}{P(\mathrm{CH})}=\frac{1}{7 \eta_{\mathrm{CH}_{4}+\mathrm{OH}}^{\mathrm{CH} / \mathrm{CD}}},
$$

and:

$$
\frac{P(\mathrm{CD})}{P\left(\mathrm{CH}_{3} \mathrm{D}\right)}=\frac{1}{3 \eta_{\mathrm{CH}_{4}+\mathrm{OH}}^{\mathrm{CH}}+1} .
$$

The final expression for the KIE becomes:

$$
\mathrm{KIE}_{\mathrm{CH}_{3} \mathrm{D}+\mathrm{OH}} \cong \frac{4 \eta_{\mathrm{CH}}^{\mathrm{CH}+\mathrm{CD}}}{3 \eta_{\mathrm{CH}_{4}+\mathrm{OH}}^{\mathrm{CH}}+1} \text {. }
$$

Again, it should be kept in mind that this simple expression is based on the assumption that the extraction of the hydrogen atom from deuterated methane is not affected by the presence of the deuterium atom (reflected by Eq. 5). The actual value of $\eta_{\mathrm{CH}_{4}+\mathrm{OH}}^{\mathrm{CH}}$ can be calculated using the Arrhenius parameters for the methane and deuterated methane reaction with hydroxyl provided by Sander et al. (2006);

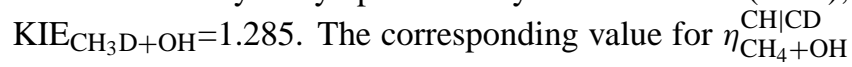

is 8.800. This means that the rate for $\mathrm{OH}$ abstracting hydrogen from $\mathrm{CH}$ in methane is almost nine times larger than the rate of deuterium abstraction from $\mathrm{CD}$. This factor will vary from one compound to another. This can be related to the activation energy (Atkinson, 1986, 1987); Due to the larger mass of the deuteron, a C-D bond is more stable than a C-H bond. Therefore, the required energy to break this bond is larger. The first IB ratio for this reaction can be calculated by applying Bayes' rule for conditional probabilities, given by $P(A \mid B)=\frac{P(B \mid A) P(A)}{P(B)}$ to Eq. (5):

$$
\alpha_{\mathrm{CH}_{3} \mathrm{D}+\mathrm{OH}}^{\mathrm{H}} \equiv P\left(\mathrm{CH} \mid \mathrm{CH}_{3} \mathrm{D}\right) \cong \frac{3}{4} P\left(\mathrm{CH} \mid \mathrm{CH}_{4}\right) \mathrm{KIE}_{\mathrm{CH}_{3} \mathrm{D}+\mathrm{OH}} .
$$

The top index $H$ indicates that this is the fraction of the product molecule that stays in the heavy branch of the oxidation chain, i.e., ends up as $\mathrm{CH}_{2} \mathrm{D}$. The second IB ratio, the fraction of deuterated methane that is transferred $\mathrm{CH}_{3}$, thus to the light chain (top index $L$ ), is:

$$
\alpha_{\mathrm{CH}_{3} \mathrm{D}+\mathrm{OH}}^{L} \equiv P\left(\mathrm{CD} \mid \mathrm{CH}_{3} \mathrm{D}\right) \cong 1-P\left(\mathrm{CH} \mid \mathrm{CH}_{3} \mathrm{D}\right) .
$$

At $288 \mathrm{~K}$, the values of the IB ratios for this reaction correspond to the values shown in Fig. 2. A practical feature of the independent bond approximation is that it enables the use of a measured KIE to derive $\eta$ as well as the IB ratios. For the simple example $\mathrm{CH}_{4}+\mathrm{OH}$ discussed here, the independent bond approximation returns the same results that have already been employed in the past using the same assumptions but a less formal derivation (Gerst and Quay, 2001; Feilberg et al., 2007b). The formal approach introduced here allows application of the same assumptions to other compounds, where the results are not immediately clear. All the steps in the $\mathrm{CH}_{4}$ oxidation sequence that are associated with isotopic branching from the deuterated to the non-deuterated reaction sequence have been examined and the derivations are shown in Appendix B. As Appendix B6 illustrates, the approach also has its limitations. It does not provide a physically plausible solution for the reaction $\mathrm{CH}_{4}+\mathrm{Cl}$, which indicates that secondary isotope effects, which are neglected in the independent bond approximation, become important. The final values for the KIE's and IB ratios are summarized in Table 1, and the required abstraction probability ratios for these reactions are summarized in Table 2 .

\subsection{Remaining reactions}

The reactions that do not have isotopic branching do not require further analysis. Table 3 shows the parameters that were introduced for these reactions in Table A1 and Table A4. 
Table 1. Reaction parameters for the reactions with a kinetic isotope effect and isotopic branching.

\begin{tabular}{|c|c|c|c|c|c|}
\hline Number & Reaction & & & Parameter & Value \\
\hline \multirow[t]{2}{*}{$\mathrm{B} 1 \mathrm{~b}$} & \multirow[t]{2}{*}{$\mathrm{CH}_{3} \mathrm{D}+\mathrm{OH}$} & $\stackrel{\alpha_{\mathrm{CH}_{3} \mathrm{D}+\mathrm{OH}}^{\mathrm{H}}}{\longrightarrow}$ & $\mathrm{CH}_{2} \mathrm{D}+\mathrm{H}_{2} \mathrm{O}$ & $\alpha_{\mathrm{CH}_{3} \mathrm{D}+\mathrm{OH}}^{H}$ & 0.964 \\
\hline & & $\stackrel{\alpha_{\mathrm{CH}_{3} \mathrm{D}+\mathrm{OH}}^{L}}{\longrightarrow}$ & $\mathrm{CH}_{3}+\mathrm{HDO}$ & $\begin{array}{l}\alpha_{\mathrm{CH}_{3} \mathrm{D}+\mathrm{OH}}^{L} \\
\mathrm{KIE}_{\mathrm{CH}_{3} \mathrm{D}+\mathrm{OH}}\end{array}$ & $\begin{array}{l}0.036 \\
1.285\end{array}$ \\
\hline \multirow[t]{2}{*}{$\mathrm{B} 2 \mathrm{~b}$} & \multirow[t]{2}{*}{$\mathrm{CH}_{3} \mathrm{D}+\mathrm{Cl}$} & $\stackrel{\alpha_{\mathrm{CH}_{3} \mathrm{D}+\mathrm{Cl}}^{\mathrm{H}}}{\longrightarrow}$ & $\mathrm{CH}_{2} \mathrm{D}+\mathrm{HCl}$ & $\alpha_{\mathrm{CH}_{3} \mathrm{D}+\mathrm{Cl}}^{H}$ & 0.935 \\
\hline & & $\stackrel{\alpha_{\mathrm{CH}} \mathrm{D}+\mathrm{Cl}}{\longrightarrow}$ & $\mathrm{CH}_{3}+\mathrm{DCl}$ & $\begin{array}{l}\alpha_{\mathrm{CH}_{3} \mathrm{D}+\mathrm{Cl}}^{L} \\
\mathrm{KIE}_{\mathrm{CH}_{3} \mathrm{D}+\mathrm{Cl}}\end{array}$ & $\begin{array}{l}0.065 \\
1.459\end{array}$ \\
\hline \multirow[t]{6}{*}{$\mathrm{B} 3 \mathrm{~b}$} & \multirow[t]{6}{*}{$\mathrm{CH}_{3} \mathrm{D}+\mathrm{O}\left({ }^{1} \mathrm{D}\right)$} & $\stackrel{\alpha_{\mathrm{CH}_{3} \mathrm{D}+\mathrm{O}\left({ }^{1} \mathrm{D}\right)}}{\longrightarrow}$ & $\mathrm{CH}_{2} \mathrm{D}+\mathrm{OH}$ & $\alpha_{\mathrm{CH}_{3} \mathrm{D}+\mathrm{O}\left({ }^{1} \mathrm{D}\right)}^{1 H}$ & 0.595 \\
\hline & & $\stackrel{\alpha^{1 L}}{\mathrm{CH}_{3} \mathrm{D}+\mathrm{O}\left({ }^{1} \mathrm{D}\right)}$ & $\mathrm{CH}_{3}+\mathrm{OD}$ & $\alpha_{\mathrm{CH}}^{1 L} \mathrm{D}+\mathrm{O}(1 \mathrm{D})$ & 0.155 \\
\hline & & $\stackrel{\alpha^{2 H}}{\mathrm{CH}_{3} \mathrm{D}+\mathrm{O}\left({ }^{1} \mathrm{D}\right)} \longrightarrow$ & $\mathrm{CH}_{2} \mathrm{DO}+\mathrm{H}$ & $\alpha_{\mathrm{CH}_{2} \mathrm{D}+\mathrm{O}\left({ }^{1} \mathrm{D}\right)}^{2 \mathrm{H}}$ & 0.159 \\
\hline & & $\stackrel{\alpha^{2 L} \mathrm{CH}_{3} \mathrm{D}+\mathrm{O}\left({ }^{1} \mathrm{D}\right)}{\longrightarrow}$ & $\mathrm{CH}_{3} \mathrm{O}+\mathrm{D}$ & $\alpha_{\mathrm{CH}_{3} \mathrm{D}+\mathrm{O}\left({ }^{1} \mathrm{D}\right)}^{2 L}$ & 0.041 \\
\hline & & $\stackrel{\alpha^{3 H}}{\mathrm{CH}_{3} \mathrm{D}+\mathrm{O}\left({ }^{1} \mathrm{D}\right)}$ & $\mathrm{CHDO}+\mathrm{H}_{2}$ & $\alpha_{\mathrm{CH}_{3} \mathrm{D}+\mathrm{O}\left({ }^{1} \mathrm{D}\right)}^{3 \mathrm{H}}$ & 0.026 \\
\hline & & $\stackrel{\alpha^{3 L}}{\mathrm{CH}_{3} \mathrm{D}+\mathrm{O}\left({ }^{1} \mathrm{D}\right)}$ & $\mathrm{CH}_{2} \mathrm{O}+\mathrm{HD}$ & $\begin{array}{l}\alpha_{\mathrm{CH}_{3} \mathrm{D}+\mathrm{O}\left({ }^{1} \mathrm{D}\right)} \\
\mathrm{KIE}_{\mathrm{CH}_{3} \mathrm{D}+\mathrm{O}\left({ }^{1} \mathrm{D}\right)}\end{array}$ & $\begin{array}{l}0.024 \\
1.058\end{array}$ \\
\hline \multirow[t]{4}{*}{ B6b } & \multirow[t]{4}{*}{$\mathrm{CH}_{2} \mathrm{DOO}+\mathrm{CH}_{3} \mathrm{OO}$} & $\stackrel{\alpha_{\mathrm{CH}_{2} \mathrm{DOO}}^{1}}{\longrightarrow}$ & $\mathrm{CH}_{2} \mathrm{DO}+\mathrm{CH}_{3} \mathrm{O}+\mathrm{O}_{2}$ & $\alpha_{\mathrm{CH}_{2} \mathrm{DOO}}^{1}$ & 0.333 \\
\hline & & $\stackrel{\alpha_{\mathrm{CH}_{2} \mathrm{DOO}}^{2 a}}{\longrightarrow}$ & $\mathrm{CH}_{2} \mathrm{DOH}+\mathrm{CH}_{2} \mathrm{O}+\mathrm{O}_{2}$ & $\alpha_{\mathrm{CH}_{2} \mathrm{DOO}}^{2 a}$ & 0.334 \\
\hline & & & $\mathrm{CH}_{3} \mathrm{OH}+\mathrm{CHDO}+\mathrm{O}_{2}$ & $\alpha_{\mathrm{CH}_{2} \mathrm{DOO}}^{2 b}$ & 0.222 \\
\hline & & $\stackrel{\alpha_{\mathrm{CH}_{2} \mathrm{DOO}}}{\longrightarrow}$ & $\mathrm{CH}_{3} \mathrm{OD}+\mathrm{CH}_{2} \mathrm{O}+\mathrm{O}_{2}$ & $\alpha_{\mathrm{CH}_{2} \mathrm{DOO}}^{2 c}$ & 0.111 \\
\hline \multirow[t]{3}{*}{$\mathrm{B} 7 \mathrm{~b}$} & \multirow[t]{3}{*}{$\mathrm{CH}_{2} \mathrm{DOH}+\mathrm{OH}$} & $\stackrel{\alpha_{\mathrm{CH}_{2} \mathrm{DOH}+\mathrm{OH}}^{1}}{\longrightarrow}$ & $\mathrm{CH}_{2} \mathrm{DO}+\mathrm{H}_{2} \mathrm{O}$ & $\alpha_{\mathrm{CH}_{2} \mathrm{DOH}+\mathrm{OH}}^{1}$ & 0.189 \\
\hline & & $\stackrel{\alpha_{\mathrm{CH}_{2} \mathrm{DOH}+\mathrm{OH}}^{2 \mathrm{H}}}{\longrightarrow}$ & $\mathrm{CHDOH}+\mathrm{H}_{2} \mathrm{O}$ & $\alpha_{\mathrm{CH}_{2} \mathrm{DOH}+\mathrm{OH}}^{2 \mathrm{H}}$ & 0.715 \\
\hline & & $\stackrel{\alpha_{\mathrm{CH}}^{2} \mathrm{DOH}+\mathrm{OH}}{\longrightarrow}$ & $\mathrm{CH}_{2} \mathrm{OH}+\mathrm{HDO}$ & $\begin{array}{l}\alpha_{\mathrm{CH}_{2} \mathrm{DOH}+\mathrm{OH}}^{2 L} \\
\mathrm{KIE}_{\mathrm{CH}_{2} \mathrm{DOH}+\mathrm{OH}}\end{array}$ & $\begin{array}{l}0.096 \\
1.262\end{array}$ \\
\hline \multirow[t]{2}{*}{$\mathrm{B} 7 \mathrm{c}$} & \multirow[t]{2}{*}{$\mathrm{CH}_{3} \mathrm{OD}+\mathrm{OH}$} & $\stackrel{\alpha_{\mathrm{CH}_{3} \mathrm{OD}+\mathrm{OH}}^{1 \mathrm{H}}}{\longrightarrow}$ & $\mathrm{CH}_{2} \mathrm{OD}+\mathrm{H}_{2} \mathrm{O}$ & $\alpha_{\mathrm{CH}_{3} \mathrm{OD}+\mathrm{OH}}^{1 H}$ & 1.000 \\
\hline & & $\stackrel{\alpha_{\mathrm{CH}_{3} \mathrm{OD}+\mathrm{OH}}^{1 L}}{\longrightarrow}$ & $\mathrm{CH}_{3} \mathrm{O}+\mathrm{HDO}$ & $\begin{array}{l}\alpha_{\mathrm{CH}_{3} \mathrm{OD}+\mathrm{OH}}^{1 L} \\
\mathrm{KIE}_{\mathrm{CH}_{3} \mathrm{OD}+\mathrm{OH}}\end{array}$ & $\begin{array}{l}0.000 \\
1.176\end{array}$ \\
\hline \multirow[t]{3}{*}{$\mathrm{B} 9 \mathrm{~b}$} & \multirow[t]{2}{*}{$\mathrm{CH}_{2} \mathrm{DOOH}+\mathrm{OH}$} & $\stackrel{\alpha_{\mathrm{CH}_{2} \mathrm{DOOH}+\mathrm{OH}}^{\longrightarrow}}{\longrightarrow}$ & $\mathrm{CH}_{2} \mathrm{DOO}+\mathrm{H}_{2} \mathrm{O}$ & $\alpha_{\mathrm{CH}, \mathrm{DOOH}+\mathrm{OH}}^{1}$ & 0.755 \\
\hline & & $\stackrel{\alpha_{\mathrm{CH}_{2} \mathrm{DOOH}+\mathrm{OH}}^{2 \mathrm{H}}}{\longrightarrow}$ & $\mathrm{CHDOOH}+\mathrm{H}_{2} \mathrm{O}$ & $\alpha_{\mathrm{CH}}^{2 \mathrm{H}} \mathrm{OOOH}+\mathrm{OH}$ & 0.216 \\
\hline & \multirow{3}{*}{$\mathrm{CH}_{2} \mathrm{DO}+\mathrm{O}_{2}$} & $\stackrel{\alpha_{\mathrm{CH}_{2} \mathrm{DOOH}+\mathrm{OH}}^{2 L}}{\longrightarrow}$ & $\mathrm{CH}_{2} \mathrm{OOH}+\mathrm{HDO}$ & $\alpha_{\mathrm{CH}_{2} \mathrm{DOOH}+\mathrm{OH}}^{2 \mathrm{~L}}$ & $\begin{array}{l}0.029 \\
1.079\end{array}$ \\
\hline \multirow[t]{2}{*}{$\mathrm{B} 10 \mathrm{~b}$} & & $\stackrel{\alpha_{\mathrm{CH}_{2} \mathrm{DO}+\mathrm{O}_{2}}^{\mathrm{H}}}{\longrightarrow}$ & $\mathrm{CHDO}+\mathrm{HO}_{2}$ & $\alpha_{\mathrm{CH}_{2} \mathrm{DO}+\mathrm{O}_{2}}^{\mathrm{H}}$ & 0.882 \\
\hline & & $\stackrel{\alpha_{\mathrm{C}} \mathrm{H}_{2} \mathrm{DO}+\mathrm{O}_{2}}{\longrightarrow}$ & $\mathrm{CH}_{2} \mathrm{O}+\mathrm{DO}_{2}$ & $\begin{array}{l}\alpha_{\mathrm{CH}_{2} \mathrm{DO}+\mathrm{O}_{2}}^{L} \\
\mathrm{KIE}_{\mathrm{CH}_{2} \mathrm{DO}+\mathrm{O}_{2}}\end{array}$ & $\begin{array}{l}0.118 \\
1.323\end{array}$ \\
\hline
\end{tabular}


Table 2. The abstraction probability ratios for the reactions with a kinetic isotope effect and isotopic branching.

\begin{tabular}{|c|c|c|c|}
\hline Number & Reaction & Ratio & Value \\
\hline B1b & $\mathrm{CH}_{3} \mathrm{D}+\mathrm{OH}$ & $\eta_{\mathrm{CH}_{4}+\mathrm{OH}}^{\mathrm{CH}}$ & 8.800 \\
\hline $\mathrm{B} 2 \mathrm{~b}$ & $\mathrm{CH}_{3} \mathrm{D}+\mathrm{Cl}$ & $\eta_{\mathrm{CH}_{4}+\mathrm{Cl}}^{\mathrm{CH} \mid \mathrm{CD}}$ & 5.610 \\
\hline \multirow[t]{5}{*}{ B3b } & $\mathrm{CH}_{3} \mathrm{D}+\mathrm{O}\left({ }^{1} \mathrm{D}\right)$ & $\eta_{\mathrm{CH}_{4}+\mathrm{O}\left({ }^{1} \mathrm{D}\right)}^{\mathrm{CD} \mid \mathrm{CH}}$ & 0.781 \\
\hline & & $\eta_{\mathrm{CH}_{4}+\mathrm{O}\left({ }^{1} \mathrm{D}\right)}^{\mathrm{CH} \mid \mathrm{HH}}$ & 22.500 \\
\hline & & $\eta_{\mathrm{CH}_{4}+\mathrm{O}\left({ }^{1} \mathrm{D}\right)}^{\mathrm{OD} \mid \mathrm{OH}}$ & 0.781 \\
\hline & & $\eta_{\mathrm{CH}_{4}+\mathrm{OH}\left({ }^{1} \mathrm{D}\right)}^{\mathrm{OH} \mid \mathrm{HH}}$ & 6.000 \\
\hline & & $\eta_{\mathrm{CH}_{4}+\mathrm{O}\left({ }^{1} \mathrm{D}\right)}^{\mathrm{HH} \mid \mathrm{HD}}$ & 1.123 \\
\hline \multirow[t]{3}{*}{$\mathrm{B} 7 \mathrm{~b}, \mathrm{~B} 7 \mathrm{c}$} & $\mathrm{CH}_{2} \mathrm{DOH}+\mathrm{OH}, \mathrm{CH}_{3} \mathrm{OD}+\mathrm{OH}$ & $\eta_{\mathrm{CH}_{3} \mathrm{OH}+\mathrm{OH}}^{\mathrm{CH} \mid \mathrm{OH}}$ & 1.889 \\
\hline & & $\eta_{\mathrm{CH}_{3} \mathrm{OH}+\mathrm{OH}}^{\mathrm{CD} \mid \mathrm{CH}}$ & 0.268 \\
\hline & & $\eta_{\mathrm{CH}_{3} \mathrm{OH}+\mathrm{OH}}^{\mathrm{OH} / \mathrm{OD}}$ & 1000 \\
\hline \multirow[t]{3}{*}{ B9b } & $\mathrm{CH}_{2} \mathrm{DOOH}+\mathrm{OH}$ & $\eta_{\mathrm{CH}_{3} \mathrm{OOH}+\mathrm{OH}}^{\mathrm{OOH} \mid \mathrm{CH}}$ & 7.000 \\
\hline & & $\eta_{\mathrm{CH}_{3} \mathrm{OOH}+\mathrm{OH}}^{\mathrm{CH}}$ & 3.730 \\
\hline & & $\eta_{\mathrm{CH}_{3} \mathrm{OOH}+\mathrm{OH}}^{\mathrm{OOH} \mid \mathrm{CD}}$ & 26.110 \\
\hline $\mathrm{B} 10 \mathrm{~b}$ & $\mathrm{CH}_{2} \mathrm{DO}+\mathrm{O}_{2}$ & $\eta_{\mathrm{CH}_{3} \mathrm{O}+\mathrm{O}_{2}}^{\mathrm{CH}}$ & 3.730 \\
\hline
\end{tabular}

Table 3. Parameters for remaining reactions.

\begin{tabular}{llllc}
\hline Number & Reaction & Parameter & \multicolumn{1}{c}{ Value } & Unit \\
\hline $\mathrm{B} 11 \mathrm{~b}$ & $\mathrm{CHDO}+\mathrm{OH}$ & $\mathrm{KIE}_{\mathrm{CHDO}+\mathrm{OH}}$ & $1.280^{\mathrm{a}}$ & \\
$\mathrm{P} 1 \mathrm{a}$ & $\mathrm{CH}_{3} \mathrm{OOH}+\mathrm{h} v$ & $\mathrm{~J}_{\mathrm{CH}_{3} \mathrm{OOH}}$ & $1.35 \times 10^{-6} \mathrm{~b}$ & $\mathrm{~s}^{-1}$ \\
$\mathrm{P} 1 \mathrm{~b}$ & $\mathrm{CH}_{2} \mathrm{DOOH}+\mathrm{h} v$ & $\mathrm{KIE}_{\mathrm{CH}_{2} \mathrm{DOOH}+\mathrm{h} v}$ & 1.000 & \\
$\mathrm{P} 2 \mathrm{a}$ & $\mathrm{CH}_{2} \mathrm{O}+\mathrm{h} v_{1}$ & $\mathrm{~J}_{\mathrm{CH}_{2} \mathrm{O}}^{\mathrm{a}}$ & $7.37 \times 10^{-5} \mathrm{~b}$ & $\mathrm{~s}^{-1}$ \\
$\mathrm{P} 2 \mathrm{~b}$ & $\mathrm{CHDO}+\mathrm{h} v_{1}$ & $\mathrm{KIE}_{\mathrm{CHDO}+\mathrm{h} \nu_{1}}$ & $1.580^{\mathrm{a}}$ & \\
P3a & $\mathrm{CH} 2 \mathrm{O}+\mathrm{h} v_{2}$ & $\mathrm{~J}_{\mathrm{CH}_{2} \mathrm{O}}^{\mathrm{b}}$ & $4.63 \times 10^{-5} \mathrm{~b}$ & $\mathrm{~s}$ \\
$\mathrm{P} 3 \mathrm{~b}$ & $\mathrm{CHDO}+\mathrm{h} v_{2}$ & $\mathrm{KIE}_{\mathrm{CHDO}+\mathrm{h} \nu_{2}}$ & $1.580^{\mathrm{a}}$ & \\
\hline
\end{tabular}

${ }^{a}$ Average measured value, taken from Feilberg et al. (2007b).

${ }^{b}$ Value derived using solar irradiance data provided by the JMA and NASA-WFF (2008).

\section{Oxidation of volatile organic compounds}

\subsection{Overview and importance of VOC reactions}

Virtually all photochemical production of $\mathrm{H}_{2}$ proceeds via formaldehyde $\left(\mathrm{CH}_{2} \mathrm{O}\right)$. The most significant contributions from VOCs to the chemical production of $\mathrm{CH}_{2} \mathrm{O}$ are the oxidation of isoprene, methanol, monoterpenes, ketones, alkanes, alkenes, aldehydes, aliphatic acids, and aromatic hydrocarbons (Novelli et al., 1999; Endresen et al., 2003; van der Werf et al., 2003; Lathière et al., 2005, 2006). Due to the involved complexity, a full treatment of the chemistry for the VOCs is impossible at the present state of knowledge and one has to chose a practical approach to implement a hydro- gen isotope scheme into a global CTM. To assess the important pathways that lead from VOC to formaldehyde, we analyzed the formaldehyde budget of a one-year simulation of the global chemistry transport model TM5 (Krol et al., 2005). This model employs the modified version of the Carbon Bond Mechanism (mCBM: Gery et al., 1989; Houweling et al., 1998). In this chemical scheme, the most relevant oxidation pathways towards formaldehyde are the oxidation of isoprene, ethene and olefins. Less important are the paraffins, methylglyoxal and the aldehydes that are not only emitted but also produced chemically from isoprene, and in case of aldehydes also from ethene. Note that some important contributing species, in particular methanol, monoterpenes and ketones, are not incorporated into the $\mathrm{mCBM}$ chemistry 
scheme. This means that roughly $35 \%$ of global VOC emissions is missing (van der Werf et al., 2003; Lathière et al., 2005, 2006).

In the present version of the TM5 model, about $30 \%$ of the $\mathrm{CH}_{2} \mathrm{O}$ is produced from VOC. On the global scale, the major contributions are direct formation from the oxidation of isoprene $(\sim 7 \%)$, olefins $(\sim 7 \%)$, and ethene $(\sim 2 \%)$ and some indirect contributions. The most important indirect contribution comes from peroxyacetyl radicals $\left(\mathrm{PA}, \mathrm{CH}_{3} \mathrm{C}(\mathrm{O}) \mathrm{OO}\right)$, which are mainly formed in the $\mathrm{OH}$ oxidation chain of isoprene and ethene. Because the relative contributions of the $\mathrm{O}_{3}$ and $\mathrm{NO}_{3}$ oxidation pathways in the formaldehyde budget were generally very low (i.e. at most $1 \%$ ), we will restrict the implementation of the isotope scheme to the reactions that involve $\mathrm{OH}$. The condensed bimolecular reactions with deuterated isoprene, olefins, and PA radicals is shown in Table $\mathrm{C} 1$ in Appendix $\mathrm{C}$ and the condensed termolecular reaction of ethene with $\mathrm{OH}$ is shown in Table $\mathrm{C} 2$ in Appendix C. These pathways are, directly or indirectly, the main contributors to the isotope budget of formaldehyde. All reaction rate parameters are from Atkinson et al. (2006) unless mentioned otherwise. The secondary products are omitted for clarity. For a similar reasons, motivated in the next section, the reactions leading to the formation of PA and deuterated PA radicals are also not shown. We will now continue to derive parameterizations for the KIE's and IB ratios for the reactions shown in Tables $\mathrm{C} 1$ and $\mathrm{C} 2$, starting with isoprene.

\subsection{The oxidation of isoprene}

\subsubsection{Chemical reaction pathway}

For the derivation of the isotope scheme for the oxidation of isoprene, we will use the reaction scheme proposed by Fan and Zhang (2004) (Fig. 4) as guideline.

In the first reaction step $\mathrm{OH}$ is added to one of the two double bonds of isoprene. This leads to the formation of four different hydroxyalkyl radicals (ISOA-ISOD). In the atmosphere, these radicals interact directly with oxygen, forming hydroxy peroxy radicals (ISO2A,ISO2D-ISO2H), hydroxyalkyl peroxy radicals (ISO2C) and hydroxy isoprene radicals (CO51). The reaction of the first two radical groups with $\mathrm{NO}$ or with other hydroxyalkyl peroxy radicals leads to the formation of methacrolein (MACR), methyl vinyl ketone (MVK) and formaldehyde, whereas the hydroxy isoprene radicals form $\mathrm{C}_{5}$ carbonyls, $\mathrm{C}_{4}$ hydroxycarbonyls, and $\mathrm{C}_{5}$ hydroxycarbonyls. The hydroxy peroxy radicals also form MACR, MVK and formaldehyde via self reactions. Via subsequent intermediate steps, MACR and MVK eventually react to form formaldehyde and PA radicals (Pöschl et al., 2000). Furthermore, Pöschl et al. (2000) also include the reaction of $\mathrm{HO}_{2}$ with the hydroxy peroxy radicals to form hydroxy hydroperoxides, that react to form MACR and MVK in the presence of $\mathrm{OH}$.

\subsubsection{Isotope parameterization}

Clearly, it is not straightforward to find an appropriate representation for the KIE's and IB ratios for this complex set of chemical reactions. Also, data on isotope effects in isoprene oxidation are only scarcely available, see e.g. Atkinson et al. (2006). Therefore, it is necessary to reduce the full mechanism to a phenomenological description of the most important features in the isoprene oxidation reaction chain. This means that only isotope effects in the intermediate steps that are expected to affect the isotopic composition of the reaction products significantly are included.

First, the majority of the formaldehyde that is formed from the hydroxyperoxy radicals ( $\mathrm{C}_{5}$ molecules) is abstracted as an entire molecule. The probability of the formation of deuterated formaldehyde is then equal to the probability that a deuterium atom is present in the active group for these reactions. For this first study and in the absence of further information, we neglect possible non-random localization of the $\mathrm{D}$ atom in isoprene that may originate from its produc-

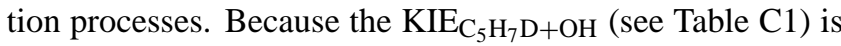
close to unity for singly deuterated isoprene (Atkinson et al., 2006), we will approximate this probability as $2 / 8=0.25$.

The fate of MVK and MACR was further investigated using the Master Chemical Mechanism (MCM: Saunders et al., 1997; Derwent et al., 1998; Saunders et al., 2003; Jenkin et al., 2003). In this scheme, the majority of the MVK and MACR molecules eventually reduce to PA radicals. MACR and MVK molecules contain 6 hydrogen atoms, whereas PA contains 3 hydrogen atoms. Following a similar approach as for the formation of formaldehyde from hydroxy peroxy radicals, we assert that the KIE is still close to unity for this transition and therefore that the probability of forming deuterated PA radicals is $3 / 6=0.50$. Deuterium atoms that do not end up in PA radicals are not necessarily lost because formaldehyde is also formed in the numerous intermediate reactions towards the formation of PA radicals. Although hydrogen atoms are added and abstracted in these intermediate reactions, we will approximate the probability of the formation of deuterated formaldehyde in these intermediate reactions as $2 / 6=0.33$.

Overall, this means that deuterated formaldehyde is formed from deuterated isoprene with a probability of $0.25+0.75 \times 0.33=0.50$, i.e. $\alpha_{\mathrm{C}_{5} \mathrm{H}_{7} \mathrm{D}+\mathrm{OH}}^{\mathrm{O}}=0.50$, and deuterated PA is formed with a probability of $0.75 \times 0.50=0.375$. Because of the underlying assumption that the KIE is unity up to the formation of the PA radical, the increase of the isotopic composition due to a decrease in the number of hydrogen atoms (MIE) is exactly cancelled by the decrease due to isotopic branching. As a result, the isotopic composition of the PA radicals will be the same as the isotopic composition of isoprene.

In the MCM, the main reaction pathways involving the destruction of PA radicals lead to the formation methylperoxy radicals $\left(\mathrm{CH}_{3} \mathrm{OO}\right)$. The main reactions paths include 


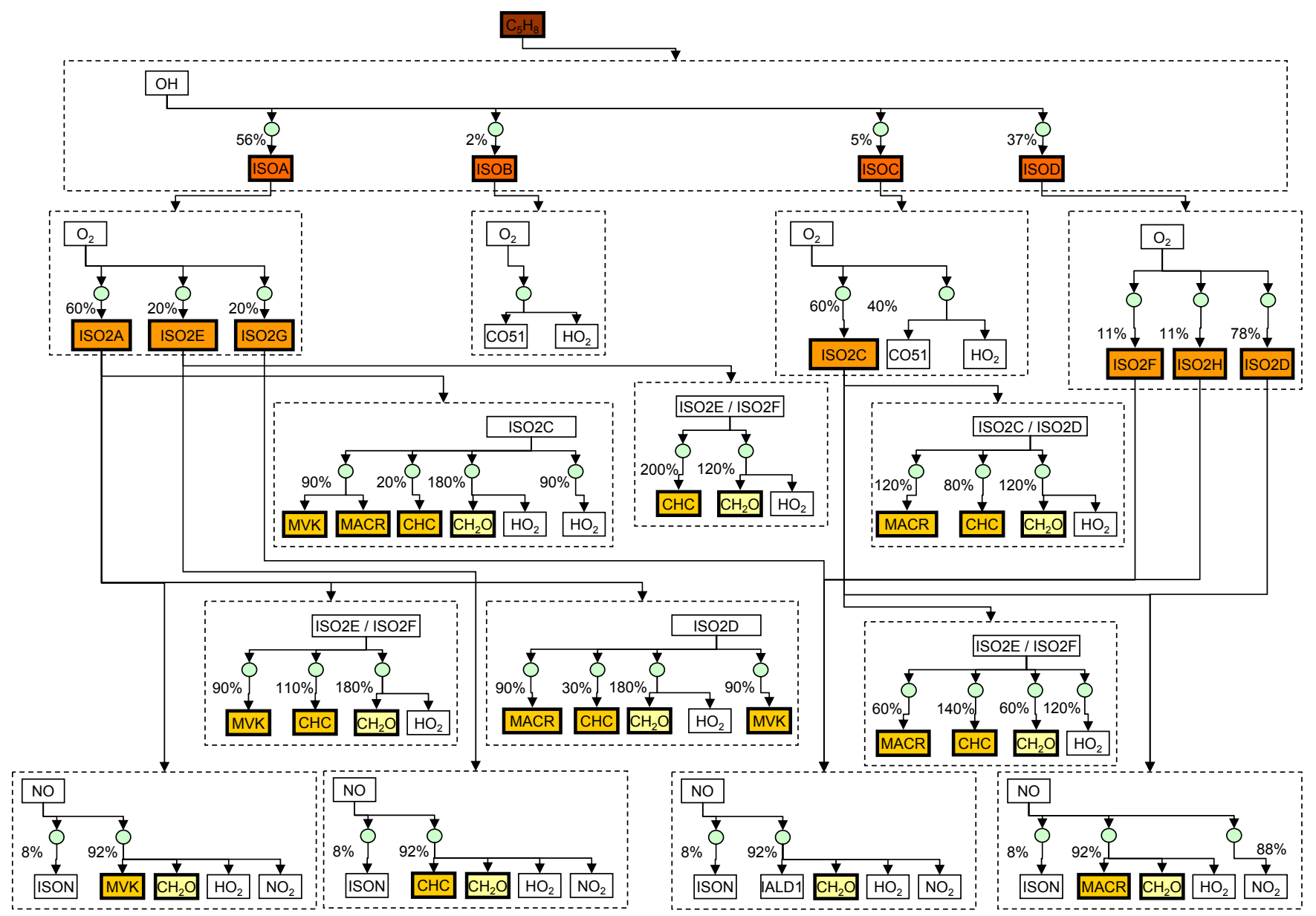

Fig. 4. Isoprene oxidation scheme, as proposed by Fan and Zhang (2004).

the self-reaction of PA, and the reactions of PA with NO or $\mathrm{HO}_{2}$. In the results of tentative global calculations with the TM5 model, the self-reaction of PA proved to add less than $1 \%$ to the formation of formaldehyde on an annual basis. Therefore we will neglect isotope effects in this reaction. Because the methyl-group from the PA radical is not altered in the reaction with $\mathrm{NO}$ or $\mathrm{HO}_{2}$, i.e. $\alpha_{\mathrm{DPA}+\mathrm{NO}}=\alpha_{\mathrm{PA}+\mathrm{NO}}, \alpha_{\mathrm{DPA}+\mathrm{HO}_{2}}=\alpha_{\mathrm{PA}+\mathrm{HO}_{2}}$, the isotopic composition of the $\mathrm{CH}_{3} \mathrm{OO}$ radicals will be the same as the composition of the original PA radicals. The $\mathrm{CH}_{3} \mathrm{OO}$ radicals are also formed in the oxidation sequence of methane (see Reaction (T1) in Table A2 in Sect. 2), and therefore we refer to the methane oxidation scheme (see Tables A1 to A4).

\subsection{The oxidation of ethene}

\subsubsection{Chemical reaction pathway}

In the global simulation with the TM5 model, $90 \%$ of the ethene $\left(\mathrm{C}_{2} \mathrm{H}_{4}\right)$ is lost via oxidation by $\mathrm{OH}$ radicals on a annual basis. The remaining $10 \%$ is removed by $\mathrm{O}_{3}$. The oxidation of $\mathrm{C}_{2} \mathrm{H}_{4}$ in the termolecular reaction with $\mathrm{OH}$ is very complex (Niki et al., 1981; Barnes et al., 1993; Orlando et al., 1998). In the first step of this reaction sequence, the hydroxyl radical adds to the double bond followed by $\mathrm{O}_{2}$ addition to the other end to form a peroxy radical, $\mathrm{HOCH}_{2} \mathrm{CH}_{2} \mathrm{O}_{2}$. In the presence of $\mathrm{NO}, \mathrm{HOCH}_{2} \mathrm{CH}_{2} \mathrm{O}$ radicals are produced that either decompose directly into formaldehyde and hydroxy methyl radicals $(>25 \%)$, or form glycol aldehyde $\left(\mathrm{HOCH}_{2} \mathrm{CHO}\right)$ in the presence of $\mathrm{O}_{2}$. The reaction of this radical with $\mathrm{OH}$ leads to the production of $80 \% \mathrm{HOCH}_{2} \mathrm{CO}_{3}$ and $20 \%$ glyoxal $(\mathrm{CHOCHO}$ ) (Bacher et al., 2001; Karunanandan et al., 2007). Further reduction of $\mathrm{HOCH}_{2} \mathrm{CO}_{3}$ leads to the formation of $\mathrm{CH}_{2} \mathrm{O}$. The photolysis of glyoxal produces $\mathrm{H}_{2}, \mathrm{CH}_{2} \mathrm{O}$, or $\mathrm{CO}$ and hydroperoxide. The possible reactions of glyoxal with $\mathrm{OH}$ do not lead to the formation of $\mathrm{CH}_{2} \mathrm{O}$, or $\mathrm{H}_{2}$. In all, approximately $90 \%$ of the ethene that reacts with $\mathrm{OH}$ will produce $\mathrm{CH}_{2} \mathrm{O}$. 


\subsubsection{Isotope parameterization}

In the reaction of $\mathrm{C}_{2} \mathrm{H}_{4}$ with $\mathrm{O}_{3}, \mathrm{CH}_{2} \mathrm{O}$ is formed in the first reaction step (Jenkin et al., 2003). Because of the small direct contribution of the oxidation of ethene to the formation of formaldehyde in TM5 $(\sim 2 \%)$, no kinetic isotope effects are considered at this stage. In the main ethene oxidation reactions that were outlined here, two out of four hydrogen atoms from the original $\mathrm{C}_{2} \mathrm{H}_{4}$ molecule will be conserved in the $\mathrm{CH}_{2} \mathrm{O}$ product. Therefore the probability that a deuterium atom from a deuterated ethene molecule is conserved is assumed to be $2 / 4=0.50$, i.e. $\alpha_{\mathrm{C}_{2} \mathrm{H}_{3} \mathrm{D}+\mathrm{OH}}^{\mathrm{H}}=0.50$. We assume that no deuterated formaldehyde is formed in other branches of the ethene oxidation chain. Therefore, the isotopic composition of the $\mathrm{CH}_{2} \mathrm{O}$ formed from $\mathrm{C}_{2} \mathrm{H}_{4}$ is similar to that of the substrate.

\subsection{The oxidation of higher olefins}

In TM5, approximately $90 \%$ of the olefins are produced from the oxidation isoprene on an annual basis. After closely examining the MCM for the oxidation of isoprene, we found that the olefins in this scheme are mainly represented by propene $\left(\mathrm{C}_{3} \mathrm{H}_{6}\right)$. In the absence of isotope measurement data, we assume that this compound is formed from isoprene without isotope effects and will therefore have the same isotopic composition. In the MCM, the majority of the reactions involving the destruction of $\mathrm{C}_{3} \mathrm{H}_{6}$ eventually leads to the formation of PA radicals, and some reactions to formaldehyde. Similar to the reasoning for MVK and MACR in Sect. 3.2 we will assume that the PA radicals formed from $\mathrm{C}_{3} \mathrm{H}_{6}$ will have the same isotopic composition as propene. However, the choice for the appropriate branching ratios of reaction T3, $\alpha_{\mathrm{C}_{\mathrm{n}} \mathrm{H}_{2 \mathrm{n}-1} \mathrm{D}+\mathrm{OH}}^{H}$ and $\alpha_{\mathrm{C}_{\mathrm{n}} \mathrm{H}_{2 \mathrm{n}-1} \mathrm{D}+\mathrm{OH}}^{L}$, is not straightforward. If $\mathrm{CH}_{2} \mathrm{O}$ is exclusively and quantitatively formed in the first reaction step, the probability for formation of deuterated formaldehyde is $\alpha_{\mathrm{C}_{n} \mathrm{H}_{2 n-1} \mathrm{D}+\mathrm{OH}}^{H}=2 / 6=0.33$. However, $\mathrm{CH}_{2} \mathrm{O}$ is also formed in the intermediate reaction steps toward the formation of the PA radicals. After the first reaction step, the probability of forming deuterated formaldehyde in the intermediate reaction steps towards the formation of $\mathrm{PA}$ is $2 / 4=0.50$. Following the derivation for the probability of the formation of deuterated $\mathrm{CH}_{2} \mathrm{O}$ in Sect. 3.2, one would arrive at a value of $0.33+0.67 \times 0.500=0.67$. As a first approximation, we will use the intermediate value of $\alpha_{\mathrm{C}_{\mathrm{n}} \mathrm{H}_{2 \mathrm{n}-1} \mathrm{D}+\mathrm{OH}}^{\mathrm{H}}=0.50$ for our calculations. Evidently, this parameter is very uncertain and, considering that the higher olefins form a significant part of the $\mathrm{CH}_{2} \mathrm{O}$ budget, this uncertainty will affect the model results significantly. We will address this issue again in the sensitivity study in the next section.

\section{Box model study}

For a first application, the isotope chemistry scheme described above was implemented into a box model configuration with a customized chemistry solver in order to examine the sensitivity of the final $\mathrm{H}_{2}$ isotopic composition to (1) individual reaction steps in the $\mathrm{CH}_{4}$ oxidation sequence and (2) VOCs and photochemical conditions. As mentioned above, the goal is to implement the scheme into a global CTM. Since at the present state of knowledge (and computing power) it may not be possible to implement it in full detail, it is important to identify the most critical parameters that determine the $\mathrm{H}_{2}$ isotopic composition. The general model setup will be described in this section, a sensitivity study to individual reaction rates and photochemical parameters in the following section.

In the box model, the concentration $\boldsymbol{c}$ (in moleccm ${ }^{-3}$ ) of $n$ chemical species can be described with the following nonlinear first order differential equation:

$\frac{d c_{i}[t]}{d t}=R_{i j}[p, T, c] c_{j}[t]$.

In this reaction, $c_{i}[t]$ is the concentration of the primary reactant species $i$ and $R_{i j}[p, T, c]$ is the rate matrix that contains the temperature and pressure dependent rate coefficients of species $i$, multiplied with the concentration of the secondary reactant species $j$. Depending on the type of reaction (bimolecular, termolecular, dissociative, or photo-dissociative) different expressions (Sander et al., 2006) are used to calculate the rate coefficients using the parameters in Tables A1 to A4 and Tables $\mathrm{C} 1$ and $\mathrm{C} 2$. Because of the non-linear behavior and the large differences in the chemical lifetime of the different species, it is not straightforward to solve this equation. We have used a modified semi-implicit Euler algorithm (Press et al., 1992) with variable time-step size to obtain solutions that are first order accurate in the convergence criterion that was set to a target precision of $\leq 0.1 \%$ o. The model does not perform transient calculations, but is always run from an initial state to equilibrium. To assess the sensitivity, we investigate changes in the equilibrium state that originate from changes in various model parameters and the initial state.

\subsection{Implementation}

The box model has been set up to incorporate also the other $\mathrm{H}_{2}$ sources and the soil deposition sink of $\mathrm{H}_{2}$ to enable qualitative comparison with previously reported isotope budgets and typical isotopic compositions. In Table 4, the relative contributions of the different terms to the global budget and their isotopic signatures are summarized. Although the magnitude of the contributions for $\mathrm{N}_{2}$ fixation sources are small, and the uncertainty of the isotopic signatures are large, it is currently believed that these processes produce highly depleted $\mathrm{H}_{2}$ (Rahn et al., 2003; Price et al., 2007) and will have a significant impact on the isotope budget. In absence of 
Table 4. Considered sources and sinks of $\mathrm{H}_{2}$ and their isotopic signatures.

\begin{tabular}{|c|c|c|}
\hline & $\begin{array}{c}\text { Relative contribution } \\
{[\%]}\end{array}$ & Isotopic signature $^{\mathrm{a}}$ \\
\hline \multicolumn{3}{|l|}{ Sources } \\
\hline Fossil fuel & 24 & $-196^{\mathrm{b}}$ \\
\hline Biomass burning & 20 & $-290^{\mathrm{b}}$ \\
\hline Ocean $\mathrm{N}_{2}$ fixation & 6 & $-628^{c}$ \\
\hline Soil $\mathrm{N}_{2}$ fixation & 4 & $-628^{\mathrm{c}}$ \\
\hline Chemistry & 46 & Calculated \\
\hline \multicolumn{3}{|l|}{ Sinks } \\
\hline Soil & 74 & $0.943^{\mathrm{b}}$ \\
\hline Chemistry & 26 & $0.568^{d}$ \\
\hline
\end{tabular}

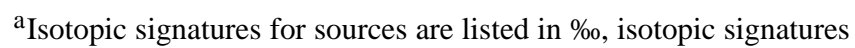
of sinks are listed as fractionation factors, i.e., the ratio of the removal rates of $\mathrm{HD}$ and $\mathrm{H}_{2}$.

${ }^{\mathrm{b}}$ From Gerst and Quay (2001).

${ }^{\mathrm{c}}$ From Price et al. (2007).

${ }^{\mathrm{d}}$ From Sander et al. (2006).

any experimental data showing less depleted $\mathrm{H}_{2}$ emissions related to $\mathrm{N}_{2}$ fixation, we will assume the values introduced by Price et al. (2007). The relative contributions were calculated by averaging the different relative source and sink contributions proposed by Ehhalt (1999), Novelli et al. (1999), Hauglustaine and Ehhalt (2002), Sanderson et al. (2003), and Price et al. (2007). For our 1-box model, we do not consider the stratospheric sink of $\mathrm{H}_{2}$.

As a first step, the global mean isotope signature for the total surface source (i.e. all sources except for the photochemical production) was calculated using the individual isotope signatures and relative contributions to the global budget according to Table 4 . This yields a value of $-309 \%$ for the combined surface emissions. The total magnitude of the surface source was then set equal to $54 / 46 \approx 1.2$ times the atmospheric source. Similarly, the soil deposition sink was set equal to 2.8 times the atmospheric sink.

An average surface temperature of $288 \mathrm{~K}$ and standard pressure $(1013.25 \mathrm{hPa})$ were used for the default calculations and no diurnal variation was considered. The branching ratios were also calculated for these conditions. Furthermore, we fixed the $\mathrm{CH}_{4}$ concentration at $1750 \mathrm{ppb}$ and assumed that the contributions of $\mathrm{Cl}$ and $\mathrm{O}\left({ }^{1} \mathrm{D}\right)$ to the $\mathrm{H}_{2}$ budget of the troposphere are negligible. The concentrations of $\mathrm{OH}\left(9.10 \times 10^{5} \mathrm{~cm}^{-3}\right), \mathrm{NO}(26.3 \mathrm{ppt})$ and $\mathrm{HO}_{2}(3.6 \mathrm{ppt})$ were taken from the yearly averaged tropospheric values from a global TM5 model simulation. The concentrations of the VOCs were tuned to match the different chemical fluxes from the VOCs to the production of formaldehyde with the values summarized in Sect. 3. For the default calculations, the iso-
Table 5. Simulated isotopic composition of the intermediate species in the methane oxidation chain.

\begin{tabular}{lc}
\hline Species & $\begin{array}{c}\text { Isotopic composition } \\
{[\% \text { o] }}\end{array}$ \\
\hline $\mathrm{CH}_{4}$ & -86 \\
$\mathrm{CH}_{3}$ & -86 \\
$\mathrm{CH}_{3} \mathrm{OO}$ & -76 \\
$\mathrm{CH}_{3} \mathrm{OOH}$ & -16 \\
$\mathrm{CH}_{3} \mathrm{O}$ & +217 \\
$\mathrm{CH}_{2} \mathrm{O}$ & +729 \\
$\mathrm{H}_{2}$ & +64 \\
\hline
\end{tabular}

topic composition of $\mathrm{CH}_{4}$ was set to $-86 \%$ o. In absence of reliable data, the isotopic composition of isoprene, ethene and the higher olefins were also set to the same value. The concentrations of all other species were initialized to zero.

It turns out that the model with the above implementation of sources simulates isotopic compositions that are within reasonable range of the real atmospheric values and thus the model allows assessment of the relative impact of various parameters on the isotopic composition of atmospheric $\mathrm{H}_{2}$.

\section{2 $\mathrm{H}_{2}$ concentration and chemical lifetime}

Figure 5 shows the simulated $\mathrm{H}_{2}$ concentration as a function of simulation time. The simulation has converged to an equilibrium concentration of $532 \mathrm{ppb}$ which is within the range of uncertainty of the average value of $531_{-6}^{+6} \mathrm{ppb}$ for the troposphere reported by Novelli et al. (1999). An exponential function with an atmospheric lifetime of 1.7 years was fitted to the data with a correlation of $R^{2}=1.00$. Considering the large uncertainties in the sink terms, this value is also within the range of uncertainty of the expected atmospheric lifetime of $2.1_{-0.7}^{+2.5}$ years (Novelli et al., 1999). It should also be kept in mind that the relative contributions of the VOCs to the formation of formaldehyde were optimized to match the results of TM5 model calculations. But apart from this optimization, using the relative contributions derived from the average of the previously reported global budgets for $\mathrm{H}_{2}$ leads to a correct prediction of the mean tropospheric average value. The very good agreement between the box model results and the global average values is considered fortuitous since the model neglects the transport processes in the atmosphere, latitudinal and seasonal variations and the stratospheric sink.

\subsubsection{Isotopic composition of $\mathrm{H}_{2}$}

Table 5 shows the isotopic composition of the key intermediate hydrogen-bearing species in the methane oxidation chain. The final value of $\delta \mathrm{D}\left(\mathrm{H}_{2}\right)=64 \%$ is not too far off from the reported average tropospheric value of $+130_{-4}^{+4} \%$ o (Gerst and Quay, 2000), especially considering that the impact of the 
Table 6. Simulated isotope budget for $\mathrm{H}_{2}$.

\begin{tabular}{lcccc}
\hline Process & $\begin{array}{c}\text { Number } \\
\text { Sources }\end{array}$ & $\begin{array}{c}\text { Relative contribution } \\
{[\%]}\end{array}$ & Signature $^{\mathrm{a}}$ & Weighted signature $^{\mathrm{a}}$ \\
$\mathrm{CH}_{2} \mathrm{O}+\mathrm{h} \nu_{1}$ & $\mathrm{P} 2$ & 53 & 95 & 50 \\
Surface sources & - & 47 & -309 & -146 \\
Total & & 100 & & -96 \\
& & & & \\
Sinks & $\mathrm{n} 12$ & 26 & 0.568 & 0.146 \\
$\mathrm{H}_{2}+\mathrm{OH}$ & - & 74 & 0.946 & 0.703 \\
Deposition & & 100 & & 0.849 \\
Total & & & & \\
\hline
\end{tabular}

${ }^{\text {a }}$ Signatures for sources are listed in $\%$, signatures of sinks are listed as fractionation factors, i.e. the ratio of the removal rates of $\mathrm{HD}_{\text {and }} \mathrm{H}_{2}$. The isotope effect associated with the troposphere-stratosphere exchange is not included into the model and would increase the tropospheric reservoir by about $37 \%$ (Price et al., 2007).

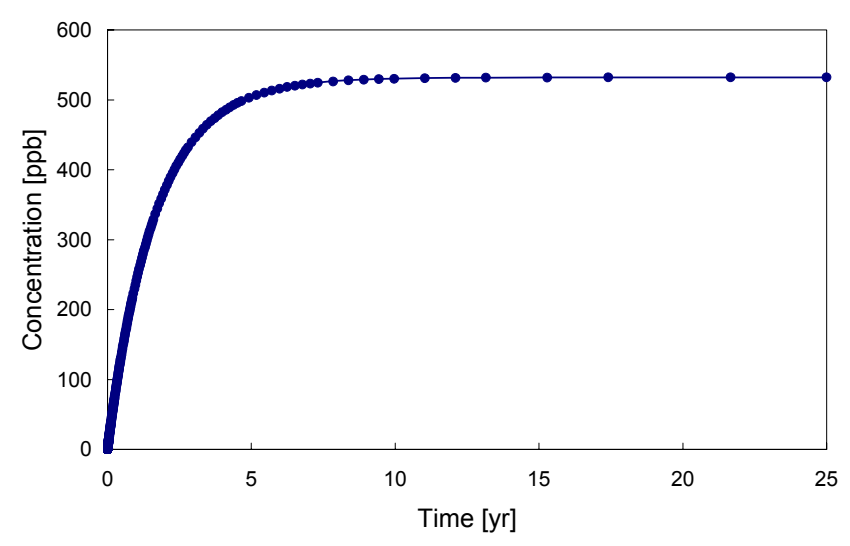

Fig. 5. Simulated $\mathrm{H}_{2}$ concentration (circles) with exponential fit $\left[H_{2}\right]=532\left(1-e^{-t / 1.7}\right)$.

stratosphere and the expected KIE's in the VOC oxidation on the isotopic composition of $\mathrm{H}_{2}$ were not taken into account. The effect of the choice of several model parameters will be investigated below.

Table 5 shows an enormous dynamic range as regards isotope fractionation from the $\mathrm{CH}_{4}$ substrate via $\mathrm{CH}_{2} \mathrm{O}$ to $\mathrm{H}_{2}$. Mainly due to the molecular isotope effect (see Sect. 2), the isotopic composition of $\mathrm{CH}_{2} \mathrm{O}$ is increased by more than $800 \%$ in $\mathrm{CH}_{2} \mathrm{O}$ relative to $\mathrm{CH}_{4}$ (note that $\delta$ values do not add linearly).

It is also interesting that there is no isotope change from $\mathrm{CH}_{4}$ to $\mathrm{CH}_{3}$. This is because the kinetic isotope effect (KIE) in $\mathrm{CH}_{4}$ removal exactly cancels out with isotopic branching (IB), and the molecular isotope effect (MIE) due to the reduction in the number of $\mathrm{H}$ atoms (see Reactions (B1a) and (B1b) in Table A1). No isotope effects are associated with the addition of $\mathrm{O}_{2}$ to $\mathrm{CH}_{3}$, but small isotope effects in the re- cycling reaction system $\mathrm{CH}_{3} \mathrm{OO}-\mathrm{CH}_{3} \mathrm{OOH}$ effectively enrich $\mathrm{CH}_{3} \mathrm{OO}$ relative to $\mathrm{CH}_{3}$. The $\mathrm{CH}_{3} \mathrm{O}$ gets strongly enriched again via the kinetic isotope effect in the $\mathrm{H}$ abstraction reaction. As will be shown below in more detail, the long-lived $\mathrm{CH}_{2} \mathrm{O}$ intermediate is then further enriched primarily by the strong isotope effects in its removal reactions. These results confirm the similar findings from a steady-state analysis presented by Feilberg et al. (2007b). In the following, we will discuss the isotope effects in the oxidation chain in detail by examining the isotope budgets for $\mathrm{H}_{2}$ and $\mathrm{CH}_{2} \mathrm{O}$.

\subsection{Isotope budgets}

\subsection{1 $\mathrm{H}_{2}$ isotope budget}

Table 6 shows the isotope budget for $\mathrm{H}_{2}$. It is obvious that the $\mathrm{H}_{2}$ produced photochemically according to our default isotope chemistry scheme is strongly enriched compared to the flux-weighted average surface source. The isotope signature of the photochemical source $(+95 \%)$, is in the lower range of reported values (Gerst and Quay, 2001; Rahn et al., 2003; Röckmann et al., 2003; Rhee et al., 2006b; Price et al., 2007). The combined source flux from surface and atmospheric sources in the model yields a source signature of $-96 \%$, and the atmospheric reservoir is further enriched to the $+64 \%$ o shown in Table 5 by the strong isotope effects in the $\mathrm{H}_{2}$ sink processes. Overall, the simple box model provides a surprisingly realistic description of the molecular $\mathrm{H}_{2}$ budget in the atmosphere in terms of the global average mixing ratio, atmospheric lifetime and global average isotopic composition. Therefore, it is suitable to investigate the sensitivity of the isotopic composition of $\mathrm{H}_{2}$ to fractionation constants in individual reaction steps, initial concentrations and isotope values and photochemical conditions as done below. But before proceeding to this step, the isotope budget of $\mathrm{CH}_{2} \mathrm{O}$ is investigated in detail. 
Table 7. Simulated isotope budget for $\mathrm{CH}_{2} \mathrm{O}$.

\begin{tabular}{lcccc}
\hline Process & $\begin{array}{c}\text { Number } \\
\text { Sources }\end{array}$ & $\begin{array}{c}\text { Relative contribution } \\
{[\%]}\end{array}$ & Signature $^{\mathrm{a}}$ & Weighted signature $^{\mathrm{a}}$ \\
$\mathrm{CH}_{3} \mathrm{OO}+\mathrm{CH}_{3} \mathrm{OO}$ & $\mathrm{B} 6$ & 0 & -539 & \\
$\mathrm{CH}_{2} \mathrm{OH}+\mathrm{O}_{2}$ & $\mathrm{~B} 8$ & 0 & -416 & 0 \\
$\mathrm{CH}_{3} \mathrm{O}+\mathrm{O}_{2}$ & $\mathrm{~B} 10$ & 81 & 217 & 0 \\
$\mathrm{C}_{5} \mathrm{H}_{8}+\mathrm{OH}$ & $\mathrm{B} 15$ & 8 & -86 & 176 \\
$\mathrm{C}_{2} \mathrm{H}_{4}+\mathrm{OH}$ & $\mathrm{T} 2$ & 2 & -86 & -6 \\
$\mathrm{C}_{\mathrm{n}} \mathrm{H}_{2 n}+\mathrm{OH}$ & $\mathrm{T} 3$ & 7 & -86 & -2 \\
$\mathrm{CH}_{2} \mathrm{OOH}$ & $\mathrm{D} 1$ & 2 & -15 & -6 \\
$\mathrm{Total}$ & & 100 & & 0 \\
$\mathrm{Sinks}_{\mathrm{CH}} \mathrm{O}+\mathrm{OH}$ & & & & 162 \\
$\mathrm{CH}_{2} \mathrm{O}+\mathrm{h} v_{1}$ & $\mathrm{~B} 11$ & 25 & 0.781 & \\
$\mathrm{CH}_{2} \mathrm{O}+\mathrm{h} \nu_{2}$ & $\mathrm{P} 2$ & 46 & 0.663 & 0.198 \\
Total & $\mathrm{P} 3$ & 29 & 0.663 & 0.290 \\
\hline
\end{tabular}

${ }^{\text {a }}$ Signatures for sources are listed in \%o, signatures of sinks are listed as fractionation factors, i.e., the ratio of the removal rates of HD and $\mathrm{H}_{2}$.

\subsection{2 $\mathrm{CH}_{2} \mathrm{O}$ isotope budget}

The hydrogen isotope budget for $\mathrm{CH}_{2} \mathrm{O}$ is shown in Table 7. The total flux-weighted isotope signature of the combined photochemical $\mathrm{CH}_{2} \mathrm{O}$ sources is $+162 \%$, and the box model reservoir is enriched to the average value of $+729 \%$ (Table 5) by the large overall KIE of 0.67 in the sink processes. This has important implications for the atmosphere. Since $\mathrm{CH}_{2} \mathrm{O}$ source and sink terms vary on diurnal time scales, it is expected that its isotopic composition varies strongly depending on whether its concentration is building up (source $>$ sink) or decreasing ( $\operatorname{sink}>$ source). This disequilibrium effect of $\mathrm{CH}_{2} \mathrm{O}$ is likely larger than the dependency on the relative removal rates of $\mathrm{CH}_{2} \mathrm{O}$ by $\mathrm{OH}$ and photolysis, which has been proposed by Rhee et al. (2006a).

Table 7 also shows the very wide range of isotope signatures for $\mathrm{CH}_{2} \mathrm{O}$ emitted from different sources that span a factor of about 4 in the $\mathrm{D} / \mathrm{H}$ ratio. It is important to note, however, that only those pathways with a significant fraction of the total production rate contribute to the isotopic composition of the final global source mix. Locally, however, the sources of $\mathrm{CH}_{2} \mathrm{O}$ may vary strongly depending on the chemical environment. The most important global $\mathrm{CH}_{2} \mathrm{O}$ source is the abstraction of $\mathrm{H}$ from the methoxy radical ( $\mathrm{Re}$ action B10), followed by the reaction of alkanes, alkenes and isoprene with $\mathrm{OH}$ (Reactions B15 and T3). It further should be kept in mind that these are model predictions that need to be tested. In particular, in our simplified parameterization of the VOC isotope chemistry, the $\mathrm{CH}_{2} \mathrm{O}$ produced from isoprene directly has an extremely enriched isotope signature, leading to an even larger overall enrichment of $\mathrm{H}_{2}$ than from $\mathrm{CH}_{4}$ oxidation alone.
Reactions (B6) and (B8) produce very depleted $\mathrm{CH}_{2} \mathrm{O}$, because $\mathrm{D}$ is preferentially lost in those reactions. However the relative contributions of these reactions to the $\mathrm{CH}_{2} \mathrm{O}$ budget are negligible on the global scale. Because of small isotope effects in the reaction of $\mathrm{CH}_{3} \mathrm{OOH}$ with $\mathrm{OH}$, see Sect. B2, the final product $\mathrm{CH}_{2} \mathrm{OOH}$ is slightly depleted and will form slightly depleted formaldehyde via Reaction (D1). However, the relative magnitude of the contribution of this reaction is too small to lead to a significant change in the isotopic composition of formaldehyde. The fractionation constants of the removal processes (B11, P2, and P3) correspond to the values stated in Table 3. It is clear that large uncertainties in these parameters lead to a large uncertainty in the predicted isotopic composition of formaldehyde.

The first published data of $\delta \mathrm{D}\left(\mathrm{CH}_{2} \mathrm{O}\right)$ (Rice and Quay, 2006) show a very large range in $\delta \mathrm{D}$ from $-294 \%$ to $+210 \%$ o in samples taken in Seattle. This on the one hand confirms the large variability that is expected based on the arguments above, but on the other hand did not show the very high enrichment $(>800 \%$ o) that the box model predicts in equilibrium. Since no further information on the samples were given by Rice and Quay (2006), it is premature to speculate whether this may arise from the disequilibrium effect discussed above or from certain source categories. In any case, the very wide range of $\mathrm{CH}_{2} \mathrm{O}$ isotope source signatures predicted with our model identifies $\mathrm{CH}_{2} \mathrm{O}$ as a particularly interesting molecule for future isotope research. Different source categories could be examined to test the validity of our isotope chemistry scheme. 
Table 8. Simulated sensitivity of isotopic composition of $\mathrm{H}_{2}$ to changes in the rate coefficients for the different reactions and reaction branches (see Tables A1 to A4 and Tables C1 to C2).

\begin{tabular}{|c|c|c|c|}
\hline Process & Number & $\begin{array}{c}\text { Isotopic change } \\
\text { Full model } \\
{[\% \text { o }]}\end{array}$ & $\begin{array}{c}\text { Isotopic change } \\
\text { Chemistry only } \\
{[\% \text { o }]}\end{array}$ \\
\hline Default & & $0(+126)$ & $0(+745)$ \\
\hline $\mathrm{CH}_{3} \mathrm{D}+\mathrm{OH}$ & $\mathrm{B} 1 \mathrm{~b}^{\mathrm{a}}$ & -49 & -127 \\
\hline $\mathrm{CH}_{2} \mathrm{DO}+\mathrm{O}_{2}$ & $\mathrm{~B} 10 \mathrm{~b}^{\mathrm{a}}$ & -58 & -148 \\
\hline $\mathrm{CH}_{2} \mathrm{O}+\mathrm{OH}$ & B11a & 17 & 44 \\
\hline $\mathrm{CHDO}+\mathrm{OH}$ & $\mathrm{B} 11 \mathrm{~b}$ & -19 & -50 \\
\hline $\mathrm{H}_{2}+\mathrm{OH}$ & $\mathrm{B} 12 \mathrm{a}$ & 27 & 160 \\
\hline $\mathrm{HD}+\mathrm{OH}$ & $\mathrm{B} 12 \mathrm{~b}$ & -18 & -119 \\
\hline $\mathrm{C}_{5} \mathrm{H}_{8}+\mathrm{OH}$ & B15a & -5 & -13 \\
\hline $\mathrm{C}_{5} \mathrm{H}_{7} \mathrm{D}+\mathrm{OH}$ & $\mathrm{B} 15 \mathrm{~b}(\mathrm{H})$ & 4 & 10 \\
\hline $\mathrm{PA}+\mathrm{NO}$ & B16a & -8 & -20 \\
\hline $\mathrm{DPA}+\mathrm{NO}$ & $\mathrm{B} 16 \mathrm{~b}$ & 8 & 21 \\
\hline $\mathrm{PA}+\mathrm{HO}_{2}$ & $\mathrm{~B} 17 \mathrm{a}$ & -1 & -2 \\
\hline $\mathrm{DPA}+\mathrm{HO}_{2}$ & $\mathrm{~B} 17 \mathrm{~b}$ & 1 & 2 \\
\hline $\mathrm{C}_{2} \mathrm{H}_{4}+\mathrm{OH}$ & $\mathrm{T} 2 \mathrm{a}$ & -1 & -3 \\
\hline $\mathrm{C}_{2} \mathrm{H}_{3} \mathrm{D}+\mathrm{OH}$ & $\mathrm{T} 2 \mathrm{~b}(\mathrm{H})$ & 1 & 3 \\
\hline $\mathrm{C}_{\mathrm{n}} \mathrm{H}_{2 \mathrm{n}}+\mathrm{OH}$ & T3a & -5 & -13 \\
\hline $\mathrm{C}_{\mathrm{n}} \mathrm{H}_{2 \mathrm{n}-1} \mathrm{D}+\mathrm{OH}$ & $\mathrm{T} 3 \mathrm{~b}(\mathrm{H})$ & 4 & 10 \\
\hline $\mathrm{CH}_{2} \mathrm{O}+\mathrm{h} v_{1}$ & $\mathrm{P} 2 \mathrm{a}$ & -24 & -86 \\
\hline $\mathrm{CHDO}+\mathrm{h} v_{1}$ & $\mathrm{P} 2 \mathrm{~b}$ & 37 & 95 \\
\hline $\mathrm{CH}_{2} \mathrm{O}+\mathrm{h} v_{2}$ & $\mathrm{P} 3 \mathrm{a}$ & 20 & 50 \\
\hline $\mathrm{CHDO}+\mathrm{h} \nu_{2}$ & $\mathrm{P} 3 \mathrm{~b}$ & -18 & -46 \\
\hline $\mathrm{H}_{2}$ deposition & - & 79 & 0 \\
\hline HD deposition & - & -81 & 0 \\
\hline $\mathrm{H}_{2} / \mathrm{HD}$ sources & - & -11 & 0 \\
\hline
\end{tabular}

${ }^{a}$ Only the branching ratios for the branch of this reaction were changed. The branching ratio that leads to the deuterated product was changed by $-10 \%$, and the other branching ratio was changed accordingly.

\subsection{Sensitivity analysis}

To investigate the global (isotope) budget of $\mathrm{H}_{2}$ using atmospheric measurements, it is important to know which processes will be actually measurable in terms of contributions to the concentration and the isotopic composition of atmospheric samples. Typical accuracies of $\mathrm{H}_{2}$ concentration measurements are in the order of $\pm 1 \%$ (Novelli et al., 1999), whereas the accuracy of isotope measurements are in the order of $\pm 3 \%$ o (Rhee et al., 2004). The induced variability of an identifiable process should be significantly larger than these limits to enable statistically significant analysis. In addition, it is important to identify those parts of the $\mathrm{CH}_{4}$ and VOC oxidation schemes that should be implemented in global models for a realistic representation. In the following subsections we will investigate the sensitivity of the isotopic composition of $\mathrm{H}_{2}$ to individual reaction and photochemical parameters.

\subsubsection{Changes in rate coefficients}

To investigate the sensitivity of the isotopic composition to changes in rate coefficients of individual isotope specific reactions (and thus fractionation constants) in the $\mathrm{CH}_{4}$ oxidation scheme, the rate coefficients of all individual reactions in the $\mathrm{CH}_{4}$ and VOC oxidation schemes of the default model were varied sequentially by $+10 \%$. It should be noted that varying individual rate constants in an isotope scheme means varying the fractionation constants by a similar amount. The chosen variations are large, and for quantitative interpretation this should be taken into account. For example the relative removal rates of $\mathrm{CH}_{4}$ and $\mathrm{CH}_{3} \mathrm{D}$ are very well constrained by experiment. However, the parameter that remains unconstrained is the relative branching between the $\mathrm{H}$ and $\mathrm{D}$ abstraction in Reaction (B1b). This means that although the kinetic isotope effect for $\mathrm{CH}_{4}$ removal is well established (Sander et al., 2006), the actual enrichment of $\mathrm{H}_{2}$ by this reaction is still uncertain because the ratio between $\mathrm{CH}_{3}$ and $\mathrm{CH}_{2} \mathrm{D}$ produced from $\mathrm{CH}_{3} \mathrm{D}$ is unknown. Therefore, rather than changing the kinetic isotope effects, we successively decreased the branching ratios for the pathways in Reaction (B1b) and (B10b) that lead to the deuterated target molecules by $-10 \%$.

Because in the full model the true changes in the chemistry scheme are damped by the surface sources and sinks, we performed the sensitivity tests both with and without surfaces sources and sinks. Table 8 shows the results of this sensitivity study.

Reactions that did not influence the isotopic composition of $\mathrm{H}_{2}$ upon variation of their rates are not shown in the table. This includes the reactions that are usually fast intermediate steps without a possibility for isotopic branching. In this case, all $\mathrm{H}$ and $\mathrm{D}$ atoms present in the reactant species are simply processed and even if large isotope fractionation occurs the reservoir is small and the effect of fractionation is negligible. The default reaction set with surface sources and sinks yields an isotopic composition of $+126 \%$, whereas the reaction set without surface sources and sinks produces an isotopic composition of $+745 \%$. The latter case is purely synthetic, but illustrates that without surface sources and sink, atmospheric chemistry alone would enrich hydrogen produced from methane and VOCs enormously because the surface sources are depleted and the surface sink has the much smaller KIE. In fact, this phenomenon is the cause for extreme enrichment in the isotopic composition of $\mathrm{H}_{2}$ in the stratosphere (Rahn et al., 2003; Röckmann et al., 2003). Especially the column without surface effects in Table 8 shows that the isotopic composition is sensitive to only a small number of reactions or processes.

In the chemistry only scheme, the largest effect is observed for a change in the rate constant for the $\mathrm{H}_{2}+\mathrm{OH}$ Reaction (B12). However, this reaction does not influence the source signature of photochemically produced $\mathrm{H}_{2}$ and its fractionation constant is well established (Note that in the 
full model, the isotope effect for this reaction is much more strongly damped than the others, because here the surface sink also contributes in addition to the sources).

For Reactions (B1) and (B10), the sensitivity to the changes in the branching ratios is large, as expected. Regarding (B10), the second $\mathrm{H}$ abstraction step, Nilsson et al. (2007) report an error of only $1 \%$ in the branching ratio between the two channels. In contrast, (B1) is only constrained by indirect evidence derived from the systematics in the rate constants of multi-deuterated methane isotopologues with $\mathrm{OH}$.

The isotope signature of the photochemical sources is the most sensitive to changes in the two $\mathrm{CH}_{2} \mathrm{O}$ photolysis channels (P2 and $\mathrm{P} 3$ ), and the reaction of $\mathrm{CH}_{2} \mathrm{O}$ with $\mathrm{OH}$ (B11). Clearly, if the molecular photolysis channel that produces HD is increased by $10 \%$, the isotopic composition of the $\mathrm{H}_{2}$ is increased dramatically. If the $\mathrm{CH}_{2} \mathrm{O}$ removal via Reaction (B11) and (P3) is increased, the remaining reservoir of $\mathrm{CH}_{2} \mathrm{O}$ is enriched and thus the $\mathrm{H}_{2}$ product is also enriched, but only as a secondary and thus smaller effect. Conversely, if CHDO is preferentially removed via Reaction (B11) and (P3), less is available for production of HD in Reaction (P2). It is again useful to put the perturbations applied in this sensitivity study into perspective by comparing them to the expected uncertainties in the measured fractionation constants. In fact, the error reported for the KIE in (B11) is $\pm 1 \%$ (Feilberg et al., 2007b), hence the imposed variations in the sensitivity study shown here are large. For $\mathrm{CH}_{2} \mathrm{O}$ photolysis, however, the range in the literature values suggests an uncertainty range of $50 \%$, and even more when the fractionation constant for the radical channel by Rhee et al. (2008) is taken into account.

Reactions (B15) and (B16) provide the isotope input from the main VOC substrate, isoprene, which also has a large effect on the total available $\mathrm{H}$ and $\mathrm{D}$ reservoirs, as reflected by the strong sensitivity. Since no strong isotope effects are included into the VOC reactions, changing those rate coefficients is effectively identical to changing the source isotope composition of the VOCs, which is one of the largest uncertainties in our photochemical model. Similarly, uncertainties in the parameters concerning the oxidation of the higher olefins (Reaction T3) will also affect the uncertainty in the global hydrogen (isotope) budget significantly. These results show that it is important to determine the isotope signatures of VOCs and include them in future hydrogen isotope chemistry schemes.

The sensitivities to changes in the rates of Reactions (B17) and (T2) are small. In practice, it will also be difficult to collect information about these and other omitted reactions from atmospheric measurements and it is not mandatory to implement isotope effects for these reactions.

Any condensed hydrogen isotope chemistry scheme should at least include the isotopic features represented by Reaction (B1), (B10), (B11), (B12), (B15), (B16), (T3), (P2), and (P3). However, it is important to note that although the chemistry involving the destruction of methanol $\left(\mathrm{CH}_{3} \mathrm{OH}\right)$ was implemented in the model (via Reaction B6), the direct emissions of this compound were not considered at the time of this study. Novelli et al. (1999) clearly indicate that this compound will probably contribute significantly (up to $30 \%$ of the total VOC contributions) to the global budget of $\mathrm{H}_{2}$ and emissions of this compound should be accounted for as well. For the same reasons, the inclusion of an oxidation scheme for the monoterpenes is recommended.

\subsubsection{Different isotopic composition of the VOCs}

In a further set of experiments, the sensitivity of the isotopic composition of $\mathrm{H}_{2}$ to a different isotopic composition of the VOCs was investigated. Decreasing the default isotopic composition of the VOCs to $-172 \%$, resulted in an decrease of $17 \%$ in the final $\mathrm{H}_{2}$ isotope signature. Although the $\mathrm{CH}_{4}$ isotope signature is well known, the average VOC signature is still unknown. This still results in a large uncertainty in the global $\mathrm{H}_{2}$ isotope budget. Nevertheless, deviations of the isotope signature in the order of $17 \%$ are measurable quantities, provided that the magnitude of other contributions to the $\mathrm{H}_{2}$ (isotope) budget are known.

\subsubsection{Formaldehyde photolysis}

The results of the above described sensitivity study combined with the known uncertainty of measured fractionation constants, clearly illustrate that the isotope effects in the photolysis of formaldehyde are by far the most critical parameters in the $\mathrm{H}_{2}$ isotope scheme. The large discrepancies between the results of Feilberg et al. (2007b) and Rhee et al. (2008) clearly call for further studies. As noted above, the isotope mass balance between the molecular channel, radical channel and total KIE reported by (Feilberg et al., 2007b) require an unrealistic distribution between the removal via the 2 channels $(77 \%$ through the molecular channel and 23\% through the radical channel), contrary to the distribution obtainable via Sander et al. (2006) (60\% through the molecular channel and $40 \%$ through the radical channel). The origin of this result is not resolved at present, but inserting the original values reported by Feilberg et al. (2007b) into the model, leads to a change in the isotope composition of the photochemical source of $-197 \%$. In this case, the isotopic composition of the total $\mathrm{H}_{2}$ reservoir changes by $-122 \%$. Looking at the results from the sensitivity study, other parameters in the budget would need large adjustments to compensate for this difference. Hence, we believe that the values reported by Feilberg et al. (2007b) should be reconsidered. On the other hand, the implementation of our isotope scheme in a simple box model might result in an incomplete representation of reality, resulting in the observed difference in isotopic composition. Implementation and verification in a full chemistry transport model is required to either validate or invalidate this finding. Therefore, the isotope effect in $\mathrm{CH}_{2} \mathrm{O}$ 
photolysis should remain the focus of current and near-future experimental investigations.

\subsection{4 $\mathrm{Cl}$ and $\mathrm{O}\left({ }^{1} \mathrm{D}\right)$ chemistry}

In the final part of this study, we show the sensitivity of the isotopic composition of $\mathrm{H}_{2}$ to $\mathrm{Cl}$ and $\mathrm{O}\left({ }^{1} \mathrm{D}\right)$ chemistry. $\mathrm{Cl}$ and $\mathrm{O}\left({ }^{1} \mathrm{D}\right)$ mixing ratios were taken from the bottom boundary layer of the stratospheric water vapor model by Zahn et al. (2006), corresponding to $7.03 \times 10^{3} \mathrm{~cm}^{-3}$ and $5.86 \times 10^{-1} \mathrm{~cm}^{-3}$ at $288 \mathrm{~K}$ at $1013.25 \mathrm{hPa}$. The contribution of $\mathrm{Cl}$ to tropospheric chemistry and its effect on various isotope budgets is a topic of current research. Average $\mathrm{Cl}$ levels of $1.8 \times 10^{4} \mathrm{~cm}^{-3}$ have been recently postulated to explain ${ }^{13} \mathrm{C}$ seasonal cycle of atmospheric $\mathrm{CH}_{4}$ (Allan et al., 2007). A recent study reported similar $\mathrm{Cl}$ concentrations in the marine boundary layer (e.g. Arsene et al., 2007). Including $\mathrm{Cl}$ chemistry at those levels leads to a decrease of $4 \%$ in the isotopic composition of the $\mathrm{H}_{2}$ reservoir whereas the contribution of $\mathrm{O}\left({ }^{1} \mathrm{D}\right)$ oxidation was found to be negligible.

\section{Conclusions}

We have derived a photochemical hydrogen isotope scheme using a simplified structure-activity relationship analysis. The basic assumption underlying our analysis is that the kinetic isotope effect (KIE) and isotopic branching (IB), i.e. the preferential removal of the lighter stable hydrogen isotopologue $(\mathrm{H})$ over the removal of the heavier hydrogen isotopologue $\mathrm{D}$ in the abstraction reactions, can be related statistically by introducing abstraction preferences for the different independent bonds in the target molecules. The different reactions of the methane oxidation chain that show isotopic branching were analyzed using Venn diagrams (Venn, 1880 ) to derive the KIE's and IB ratios based on abstraction preferences for the different independent bonds of the target molecules of these reactions. A similar but more phenomenological approach was chosen for the oxidation reactions for the VOCs.

The resulting scheme was implemented and evaluated in a 1-D box model. The resulting $\mathrm{H}_{2}$ equilibrium concentration of $532 \mathrm{ppb}$ was within the range of uncertainty of the average value of $531_{-6}^{+6} \mathrm{ppb}$ for the troposphere reported by Novelli et al. (1999). The simulated atmospheric lifetime of 1.7 years was also within the range of uncertainty of the expected atmospheric lifetime of $2.1_{-0.7}^{+2.5}$ years.

The isotopic composition of $\mathrm{H}_{2}$ was evaluated in Sect. 4.2.1. Although the simple 1-D model was not intended for determination of the hydrogen budget, the final value of $\delta \mathrm{D}\left(\mathrm{H}_{2}\right)=64 \%$ o was reasonably close to the reported average tropospheric value of $+130_{-4}^{+4} \%$ o (Gerst and Quay, 2000). Mainly due to the molecular isotope effects in the chemical source, viz. the enrichment in terms of $\delta \mathrm{D}$ due to the removal of $\mathrm{H}$ atoms, and the strong isotope effects in its removal reactions, the isotopic composition of $\mathrm{CH}_{2} \mathrm{O}$ was found to increase by more than $800 \%$ in $\mathrm{CH}_{2} \mathrm{O}$ relative to $\mathrm{CH}_{4}$. These results confirm similar findings from a steadystate analysis presented by Feilberg et al. (2007b). Considering chemistry only, the isotopic composition of $\mathrm{H}_{2}$ proved to be most sensitive to the branching ratio of the reaction of $\mathrm{CH}_{3} \mathrm{D}$ with $\mathrm{OH}$ (B1b). The composition was found to be one order less sensitive to the KIE of the photochemical reactions involving the destruction of $\mathrm{CH}_{2} \mathrm{O},(\mathrm{B} 11, \mathrm{P} 2$, and $\mathrm{P} 3$ ), and the KIE of the oxidation reaction of $\mathrm{H}_{2}$ itself (B12). The oxidation of isoprene, the peroxyacetyl radicals, and higher olefins were found to be of similar importance. When considering all processes that determine the isotopic composition of $\mathrm{H}_{2}$, the isotopic composition was found to be most sensitive to the fractionation constant of deposition.

Although these findings indicated that the model is able to reproduce the basic required features adequately, our results depend critically on several parameters, as the results for the isotope budgets (see Sect. 4.3) clarified.

The main recommendations for future work are:

- Implement the proposed scheme in a global CTM to simulate the global isotope composition of $\mathrm{H}_{2}$

- Measure the isotopic composition of $\mathrm{CH}_{2} \mathrm{O}$ under different photochemical conditions

- Resolve the isotopic mass balance in the $\mathrm{CH}_{2} \mathrm{O}$ photolysis channels

- Measure the isotopic composition of VOCs and their KIE's

\section{Appendix A}

\section{Overview of full $\mathrm{CH}_{4}$ oxidation reactions}

Please view Tables A1 to A4.

\section{Appendix B}

\section{Detailed derivation of KIEs and branching ratios for critical reactions in the $\mathrm{CH}_{4}$ oxidation chain}

This appendix contains the full derivation of the kinetic isotope effects and isotopic branching ratios for all remaining reactions in the methane oxidation chain. The rationale behind these derivations is similar to the approach introduced for the reaction of $\mathrm{CH}_{4}$ and $\mathrm{OH}$ in Sect. 2.1.

\section{B1 $\mathrm{CH}_{3} \mathrm{O}+\mathrm{O}_{2}$ reaction}

The isotope effects involved with this reaction were recently investigated by Nilsson et al. (2007). Although the reaction kinetics of the methoxy radical and oxygen are quite different 
Table A1. Considered bimolecular methane oxidation reactions.

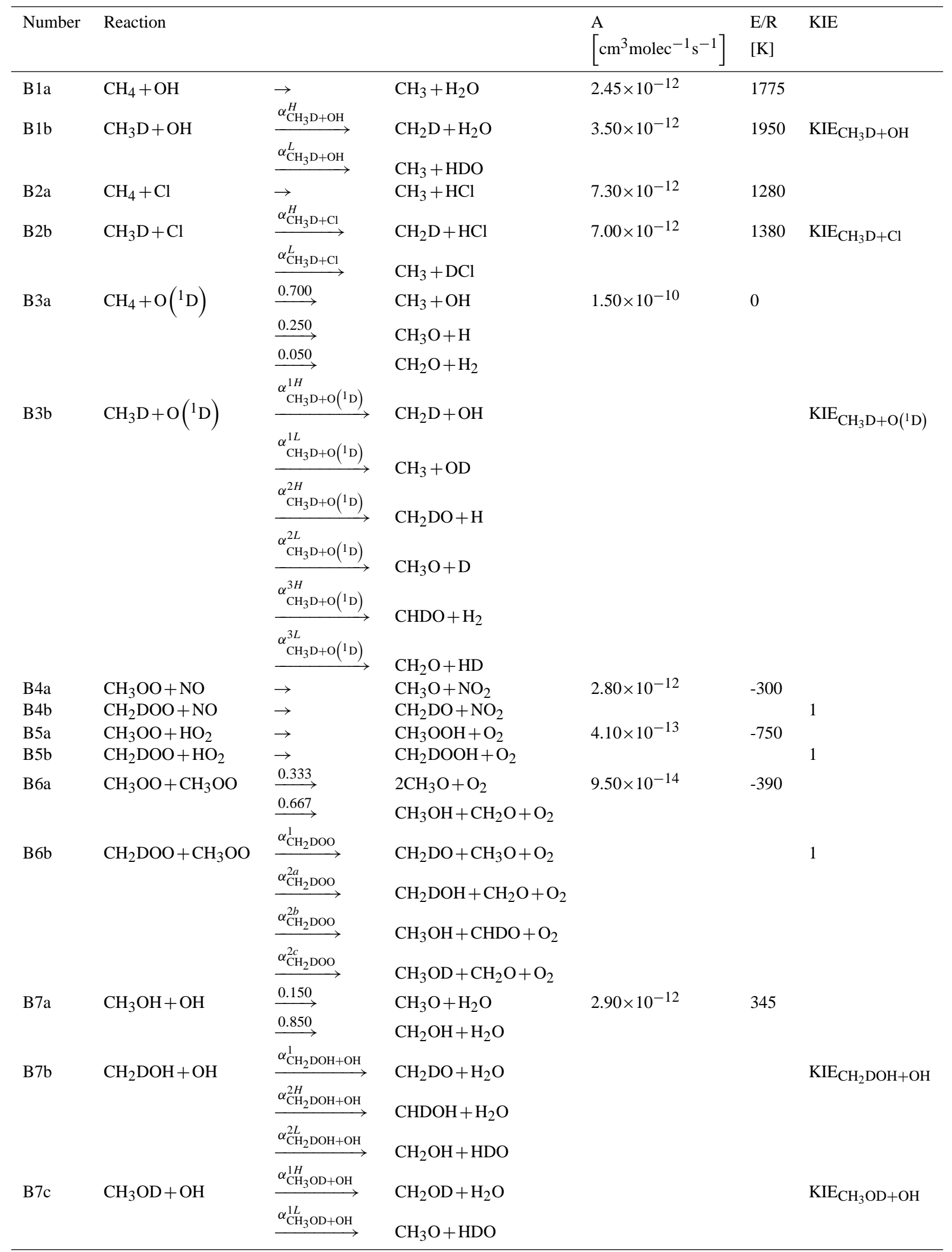


Table A1. Continued.

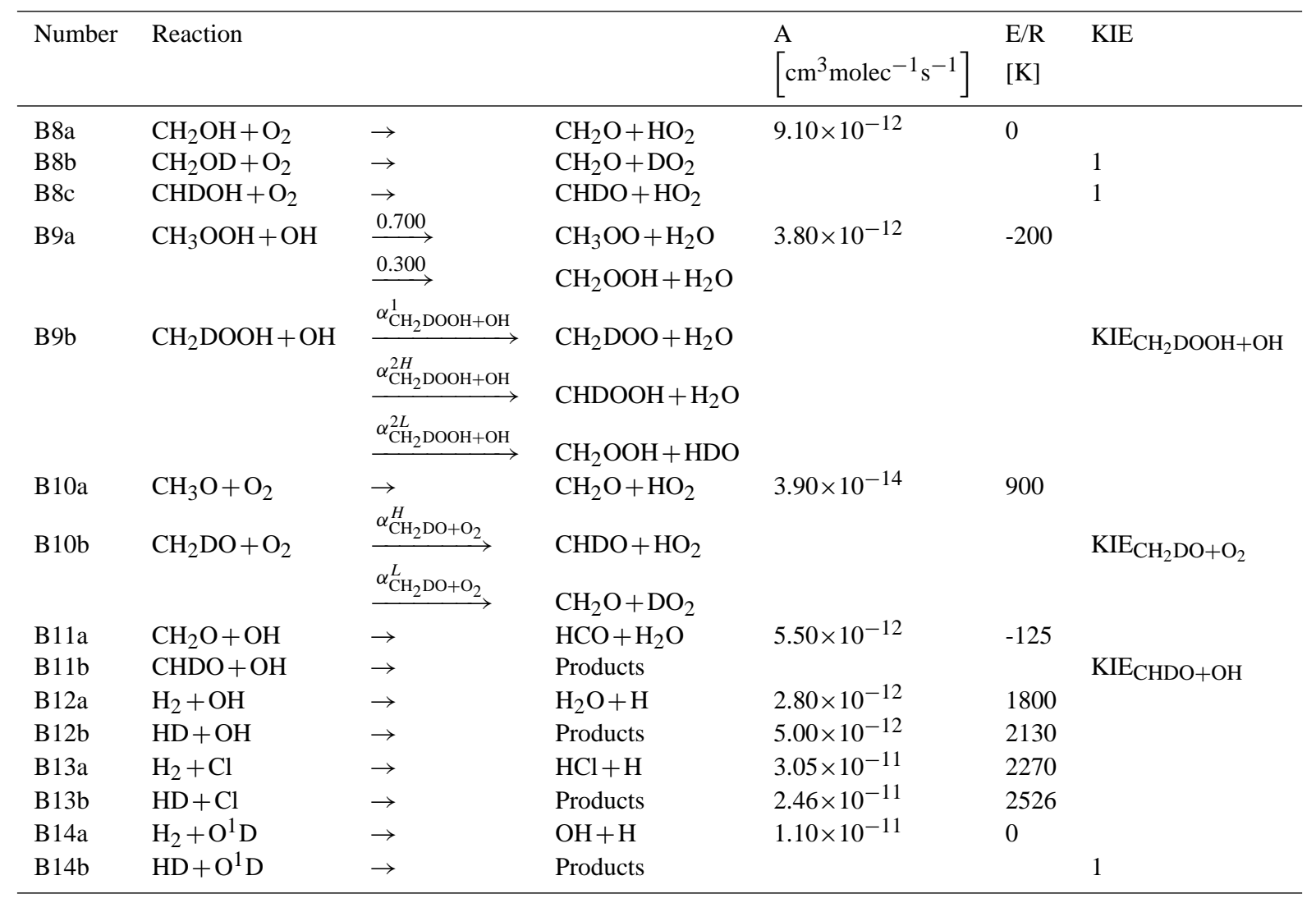

Table A2. Considered termolecular methane oxidation reactions.

\begin{tabular}{|c|c|c|c|c|c|c|c|}
\hline Number & Reaction & & & $\begin{array}{c}\mathrm{k}_{0} \\
{\left[\mathrm{~cm}^{6} \mathrm{molec}^{-2} \mathrm{~s}^{-1}\right]}\end{array}$ & $\begin{array}{c}\mathrm{k}_{u} \\
{\left[\mathrm{~cm}^{3} \mathrm{molec}^{-1} \mathrm{~s}^{-1}\right]}\end{array}$ & $\mathrm{n}$ & $\mathrm{m}$ \\
\hline T1a & $\mathrm{CH}_{3}+\mathrm{O}_{2}$ & $\rightarrow$ & $\mathrm{CH}_{3} \mathrm{OO}$ & $4.0 \times 10^{-31}$ & $1.2 \times 10^{-12}$ & 3.6 & -1.1 \\
\hline $\mathrm{T} 1 \mathrm{~b}$ & $\mathrm{CH}_{2} \mathrm{D}+\mathrm{O}_{2}$ & $\rightarrow$ & $\mathrm{CH}_{2} \mathrm{DOO}$ & $4.0 \times 10^{-31}$ & $1.2 \times 10^{-12}$ & 3.6 & -1.1 \\
\hline
\end{tabular}

Table A3. Considered dissociation methane oxidation reactions.

\begin{tabular}{lllll}
\hline Number & Reaction & & & $\begin{array}{c}\mathrm{k} \\
{\left[\mathrm{s}^{-1}\right]}\end{array}$ \\
\hline D1a & $\mathrm{CH}_{2} \mathrm{OOH}$ & $\rightarrow$ & $\mathrm{CH}_{2} \mathrm{O}+\mathrm{OH}$ & $1.0 \times 10^{-6}$ \\
D1b & $\mathrm{CHDOOH}$ & $\rightarrow$ & $\mathrm{CHDO}+\mathrm{OH}$ & $1.0 \times 10^{-6}$ \\
\hline
\end{tabular}

from the kinetics involved with the methane-hydroxyl reaction, we choose to follow a similar approach to derive the IB ratios using the KIE reported by Nilsson et al. (2007). Figure $\mathrm{B} 1$ shows the Venn diagram for this reaction.
As the derivation is equivalent to the derivation shown in the previous section, we only state the final expression for the KIE:

$\mathrm{KIE}_{\mathrm{CH}_{2} \mathrm{DO}+\mathrm{O}_{2}} \cong \frac{3 \eta_{\mathrm{CH}}^{\mathrm{CH} \mid \mathrm{CD}}+\mathrm{O}_{2}}{2 \eta_{\mathrm{CH}_{3} \mathrm{O}+\mathrm{O}_{2}}^{\mathrm{CH} \mid \mathrm{CD}}+1}$,

and for the first and second IB ratio, respectively:

$$
\begin{aligned}
\alpha_{\mathrm{CH}_{2} \mathrm{DO}+\mathrm{O}_{2}}^{\mathrm{H}} & \equiv P\left(\mathrm{CH} \mid \mathrm{CH} \mathrm{H}_{2} \mathrm{DO}\right) \\
& \cong \frac{2}{3} P\left(\mathrm{CH} \mid \mathrm{CH}_{3} \mathrm{O}\right) \mathrm{KIE}_{\mathrm{CH}_{2} \mathrm{DO}+\mathrm{O}_{2}},
\end{aligned}
$$

and:

$\alpha_{\mathrm{CH}_{2} \mathrm{DO}+\mathrm{O}_{2}}^{L} \equiv P\left(\mathrm{CD} \mid \mathrm{CH}_{2} \mathrm{DO}\right) \cong 1-P\left(\mathrm{CH} \mid \mathrm{CH}_{2} \mathrm{DO}\right)$. 
Table A4. Considered photo dissociation methane oxidation reactions.

\begin{tabular}{|c|c|c|c|c|c|}
\hline Number & Reaction & & & $\begin{array}{c}\mathrm{J} \\
{\left[\mathrm{s}^{-1}\right]}\end{array}$ & KIE \\
\hline P1a & $\mathrm{CH}_{3} \mathrm{OOH}+\mathrm{h} v$ & $\rightarrow$ & $\mathrm{CH}_{3} \mathrm{O}+\mathrm{OH}$ & $\mathrm{J}_{\mathrm{CH}_{3} \mathrm{OOH}}$ & \\
\hline $\mathrm{P} 1 \mathrm{~b}$ & $\mathrm{CH}_{2} \mathrm{DOOH}+\mathrm{h} v$ & $\rightarrow$ & $\mathrm{CH}_{2} \mathrm{DO}+\mathrm{OH}$ & & $\mathrm{KIE}_{\mathrm{CH}_{2} \mathrm{DOOH}+\mathrm{h} \nu}$ \\
\hline $\mathrm{P} 2 \mathrm{a}$ & $\mathrm{CH}_{2} \mathrm{O}+\mathrm{h} v_{1}$ & $\rightarrow$ & $\mathrm{H}_{2}+\mathrm{CO}$ & $\mathrm{J}_{\mathrm{CH}_{2} \mathrm{O}}^{\mathrm{a}}$ & \\
\hline $\mathrm{P} 2 \mathrm{~b}$ & $\mathrm{CHDO}+\mathrm{h} v_{1}$ & $\rightarrow$ & $\mathrm{HD}+\mathrm{CO}$ & & $\mathrm{KIE}_{\mathrm{CHDO}+\mathrm{h} v_{1}}$ \\
\hline P3a & $\mathrm{CH}_{2} \mathrm{O}+\mathrm{h} v_{2}$ & $\rightarrow$ & $\mathrm{H}+\mathrm{HCO}$ & $\mathrm{J}_{\mathrm{CH}_{2} \mathrm{O}}^{\mathrm{b}}$ & \\
\hline $\mathrm{P} 3 \mathrm{~b}$ & $\mathrm{CHDO}+\mathrm{h} v_{2}$ & $\rightarrow$ & Products & & $\mathrm{KIE}_{\mathrm{CHDO}+\mathrm{h} \nu_{2}}$ \\
\hline
\end{tabular}

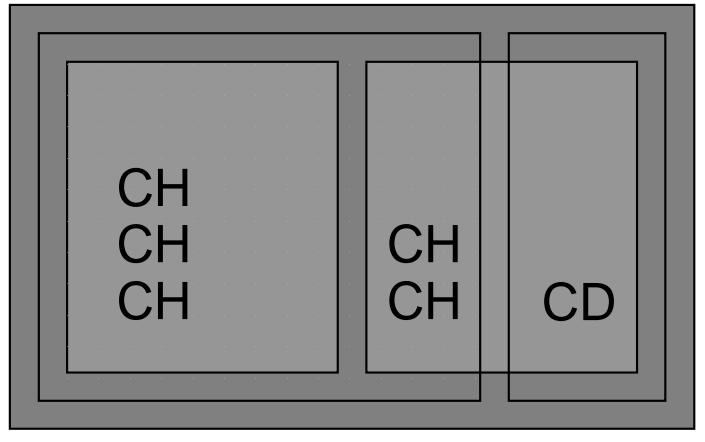

Fig. B1. Venn diagram for $\mathrm{CH}_{3} \mathrm{O}+\mathrm{O}_{2}$ reaction.

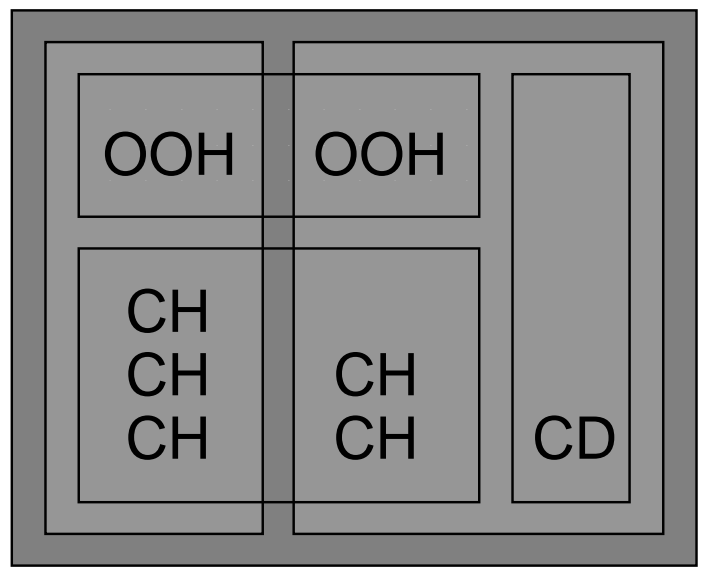

Fig. B2. Venn diagram for $\mathrm{CH}_{3} \mathrm{OOH}+\mathrm{OH}$ reaction.

We re-emphasize the underlying assumption that the removal of the hydrogen atoms from $\mathrm{CH}_{2} \mathrm{DO}$ is not affected by the presence of a deuterium atom. In contrast to the assumption followed by Feilberg et al. (2007b) the value of $\eta_{\mathrm{CH}_{3} \mathrm{O}+\mathrm{O}_{2}}^{\mathrm{CH}}$ differs from the value used for the methane-hydroxyl reaction because the branching ratios reported by Nilsson et al. (2007) yield a KIE equal to 1.323 . The corresponding value for $\eta_{\mathrm{CH}_{3} \mathrm{O}+\mathrm{O}_{2}}^{\mathrm{CH}}$ is 3.730. Because no relevant measurement data are available for the active $\mathrm{CH}_{3}$-group of the molecules discussed in the next sections, we will also assume this value for these molecules.

\section{B2 $\mathrm{CH}_{3} \mathrm{OOH}+\mathrm{OH}$ reaction}

For the reaction of methyl hydroperoxide with hydroxyl, the derivation becomes more complicated. In fact, there are now two functional groups; The methyl and hydroperoxide group. The non-deuterated reaction has two pathways:

$$
\begin{aligned}
\mathrm{CH}_{3} \mathrm{OOH}+\mathrm{OH} & \stackrel{0.700}{\longrightarrow} \mathrm{CH}_{3} \mathrm{OO}+\mathrm{H}_{2} \mathrm{O}, \\
\stackrel{0.300}{\longrightarrow} & \mathrm{CH}_{2} \mathrm{OOH}+\mathrm{H}_{2} \mathrm{O},
\end{aligned}
$$

and the abstraction probabilities can be visualized by the Venn diagram shown in Fig. B2.

For the deuterated form, it is important to note that methyl hydroperoxide is formed from the reaction of the methyl peroxy radical with hydroperoxide. The sequence of the preceding reaction steps leads to the assertion that the deuterium atom present in the methyl peroxy radical remains situated in the methyl group. Furthermore, it is considered unlikely that the methyl peroxy radical will encounter a deuterated hydroperoxide molecule. This means that, apart from the KIE introduced by the second branch represented by Eq. (B5), the first branch (Eq. B4) remains unchanged. We can formulate the branching ratios of the non-deuterated reaction as:

$P\left(\mathrm{OOH} \mid \mathrm{CH}_{3} \mathrm{OOH}\right)=0.700$,

and:

$P\left(\mathrm{CH} \mid \mathrm{CH}_{3} \mathrm{OOH}\right)=0.300$.

Furthermore, we assume that the abstraction probability of $\mathrm{H}$ from methyl groups and $\mathrm{OOH}$ groups is similar for both isotopologues:

$P\left(\mathrm{CH}_{3} \mathrm{OOH} \cap \mathrm{OOH}\right) \cong P\left(\mathrm{CH}_{2} \mathrm{DOOH} \cap \mathrm{OOH}\right)$, and:

$P\left(\mathrm{CH}_{3} \mathrm{OOH} \cap \mathrm{CH}\right) \cong \frac{3}{2} P\left(\mathrm{CH}_{2} \mathrm{DOOH} \cap \mathrm{CH}\right)$. 
The inverse of the KIE for this reaction can be written as:

$$
\begin{aligned}
& \mathrm{KIE}_{\mathrm{CH}_{2} \mathrm{DOOH}+\mathrm{OH}}^{-1}= \\
& \frac{P\left(\mathrm{CH}_{2} \mathrm{DOOH} \cap \mathrm{OOH}\right)+P\left(\mathrm{CH}_{2} \mathrm{DOOH} \cap \mathrm{CH}\right)+P\left(\mathrm{CH}_{2} \mathrm{DOOH} \cap \mathrm{CD}\right)}{P\left(\mathrm{CH}_{3} \mathrm{OOH} \cap \mathrm{OOH}\right)+P\left(\mathrm{CH}_{3} \mathrm{OOH} \cap \mathrm{CH}\right)}
\end{aligned}
$$

We will reduce the three parts of the numerator-denominator couples on the right-hand side of this expression separately. Using Eq. (B8), the first numerator-denominator term can also be written as:

$$
\begin{gathered}
\frac{P\left(\mathrm{CH}_{2} \mathrm{DOOH} \cap \mathrm{OOH}\right)}{P\left(\mathrm{CH}_{3} \mathrm{OOH} \cap \mathrm{OOH}\right)+P\left(\mathrm{CH}_{3} \mathrm{OOH} \cap \mathrm{CH}\right)} \\
\cong \frac{1}{1+\frac{P\left(\mathrm{CH}_{3} \mathrm{OOH} \cap \mathrm{CH}\right)}{P\left(\mathrm{CH}_{3} \mathrm{OOH}\right)}} \equiv A .
\end{gathered}
$$

$A$ can be calculated explicitly using Eqs. (B6) and (B7). Using Eq. (B9), the second numerator-denominator term on the right-hand side of Eq. (B10) becomes:

$$
\begin{gathered}
\frac{P\left(\mathrm{CH}_{2} \mathrm{DOOH} \cap \mathrm{CH}\right)}{P\left(\mathrm{CH}_{3} \mathrm{OOH} \cap \mathrm{OOH}\right)+P\left(\mathrm{CH}_{3} \mathrm{OOH} \cap \mathrm{CH}\right)} \\
\cong \frac{1}{1+\frac{P\left(\mathrm{CH}_{3} \mathrm{OOH} \cap \mathrm{OOH}\right)}{P\left(\mathrm{CH}_{3} \mathrm{OOH} \cap \mathrm{CH}\right)}} \equiv B .
\end{gathered}
$$

The third and last term on the right-hand side of Eq. (B10) can be simplified using:

$$
\begin{aligned}
P\left(\mathrm{CD} \mid \mathrm{CH}_{2} \mathrm{DOOH}\right) & =\frac{1}{1 \eta_{\mathrm{CH}_{3} \mathrm{OOH}+\mathrm{OH}}^{\mathrm{OOH} \mid \mathrm{CD}}+2 \eta_{\mathrm{CH}_{3} \mathrm{OOH}+\mathrm{OH}}^{\mathrm{CH}}+1} \\
& \equiv X .
\end{aligned}
$$

In this expression, $\eta_{\mathrm{CH}_{3} \mathrm{OOH}+\mathrm{OH}}^{\mathrm{OOH}}$ is the ratio between the abstraction probability for hydrogen atoms from the hydroperoxide group and the abstraction probability for deuterium atoms from a C-D bond. $\eta_{\mathrm{CH}_{3} \mathrm{OOH}+\mathrm{OH}}^{\mathrm{OOH}}$ can be calculated as $\eta_{\mathrm{CH}_{3} \mathrm{OOH}+\mathrm{OH}}^{\mathrm{OOH}} \eta_{\mathrm{CH}}^{\mathrm{CH} \mid \mathrm{OOH}+\mathrm{OH}}$, where $\eta_{\mathrm{CH}_{3} \mathrm{OOH}+\mathrm{OH}}^{\mathrm{OOH}}$ can be calculated using Eqs. (B6) or (B7). For reasons stated in Sect. B1, we will assume that $\eta_{\mathrm{CH}_{3} \mathrm{OOH}+\mathrm{OH}}^{\mathrm{CH}}$ has the same value as $\eta_{\mathrm{CH}_{3} \mathrm{O}+\mathrm{O}_{2}}^{\mathrm{CH}}$. Using the definition of the conditional probability on Eq. (B13), the simplified expression for the third numerator term on the right-hand side of Eq. (B10) becomes:

$$
\begin{aligned}
& \frac{P\left(\mathrm{CH}_{2} \mathrm{DOOH} \cap \mathrm{CD}\right)}{P\left(\mathrm{CH}_{3} \mathrm{OOH} \cap \mathrm{OOH}\right)+P\left(\mathrm{CH}_{3} \mathrm{OOH} \cap \mathrm{CH}\right)} \\
& \cong X \mathrm{KIE}_{\mathrm{CH}_{2} \mathrm{DOOH}+\mathrm{OH}}^{-1} .
\end{aligned}
$$

Now we can write down the final expression for the KIE for this reaction:

$\mathrm{KIE}_{\mathrm{CH}_{2} \mathrm{DOOH}+\mathrm{OH}} \cong \frac{1-X}{A+B}$.

Using Eq. (B8), the branching ratio of the deuterated reaction described in Eq. (B4) becomes:

$$
\begin{aligned}
\alpha_{\mathrm{CH}_{2} \mathrm{DOOH}+\mathrm{OH}}^{1} & \equiv P\left(\mathrm{OOH} \mid \mathrm{CH}_{2} \mathrm{DOOH}\right) \\
& \cong P\left(\mathrm{OOH} \mid \mathrm{CH}_{3} \mathrm{OOH}\right) \mathrm{KIE}_{\mathrm{CH}_{2} \mathrm{DOOH}+\mathrm{OH}} .
\end{aligned}
$$

Finally, Eq. (B9) is used to calculate the IB ratios for the deuterated version of the reaction defined by Eq. (B5):

$$
\begin{aligned}
\alpha_{\mathrm{CH}_{2} \mathrm{DOOH}+\mathrm{OH}}^{2 \mathrm{H}} & \equiv P\left(\mathrm{CH} \mid \mathrm{CH}_{2} \mathrm{DOOH}\right) \\
& \cong \frac{2}{3} P\left(\mathrm{CH} \mid \mathrm{CH}_{3} \mathrm{OOH}\right) \mathrm{KIE}_{\mathrm{CH}_{2} \mathrm{DOOH}+\mathrm{OH}},
\end{aligned}
$$

and:

$$
\begin{aligned}
\alpha_{\mathrm{CH}_{2} \mathrm{DOOH}+\mathrm{OH}}^{2 L} \equiv & P\left(\mathrm{CD} \mid \mathrm{CH}_{2} \mathrm{DOOH}\right) \\
\cong & 1-P\left(\mathrm{OOH} \mid \mathrm{CH}_{2} \mathrm{DOOH}\right) \\
& -P\left(\mathrm{CH} \mid \mathrm{CH}_{2} \mathrm{DOOH}\right) .
\end{aligned}
$$

\section{$\mathrm{B3} \mathrm{CH}_{3} \mathrm{OO}+\mathrm{CH}_{3} \mathrm{OO}$ reaction}

The branching ratios of the two reaction paths of the selfreaction of non-deuterated methyl peroxy radicals $\left(\mathrm{CH}_{3} \mathrm{OO}\right)$ in Table A1 (Reaction B6a) were taken from the recommendations by Sander et al. (2006) for $288 \mathrm{~K}$. The exact mechanism of this reaction is an ongoing subject of numerous studies (e.g. Weaver et al., 1975; Minato et al., 1978; Lightfoot et al., 1992; Henon et al., 1997; Tyndall et al., 1998, 2001; Feria et al., 2004). The current view is that first an unstable intermediate is formed that can either decompose into its reactants or decompose form the products shown for the two reaction channels. Because of this complexity and lack of experimental data about isotope effects in this reaction, we neglect the isotope effect in Reaction (B6a) in Table A1. The sensitivity study of the box model shown in Sect. 4.4 also shows that isotope effects in this reaction are not significant for the final $\mathrm{H}_{2}$ product. Therefore, the IB ratios for reaction channels B6b can be easily calculated using the non-deuterated branching ratios and a statistical probability for the three possible channels, i.e. $\alpha_{\mathrm{CH}_{2} \mathrm{DOO}}^{1}=0.333$, $\alpha_{\mathrm{CH}_{2} \mathrm{DOO}}^{2 a}=0.334, \alpha_{\mathrm{CH}_{2} \mathrm{DOO}}^{2 b}=0.222$, and $\alpha_{\mathrm{CH}_{2} \mathrm{DOO}}^{2 c}=0.111$.

\section{B4 $\mathrm{CH}_{3} \mathrm{OH}+\mathrm{OH}$ reaction}

The reaction of methanol $\left(\mathrm{CH}_{3} \mathrm{OH}\right)$ with $\mathrm{OH}$ has also been a subject of numerous studies (e.g. Hess and Tully, 1989; McCaulley et al., 1989; Jiménez et al., 2003; Atkinson et al., 2006). In the proposed hydrogen isotope scheme, the reaction of deuterated methyl peroxide with non-deuterated methyl peroxide leads to the formation of two types of deuterated methanol molecules, i.e. $\mathrm{CH}_{2} \mathrm{DOH}$ and $\mathrm{CH}_{3} \mathrm{OD}$. These molecules react with $\mathrm{OH}$ via Reaction $(\mathrm{B} 7 \mathrm{~b})$ and (B7c), shown in Table A1. The reaction possibilities for these two isotopologues are shown in Fig. B3.

A strong KIE $=3.015_{-0.779}^{+1.206}$ was measured by McCaulley et al. (1989) for deuterated methanol with fully deuterated methyl groups, whereas within the limits of measurement uncertainty, no significant KIE was observable for methanol isotopologues with a deuterium atom located in the hydroxyl group. However, this reaction was only investigated using deuterated hydroxyl radicals. Their data also indicate that the KIE for a fully deuterated methanol molecule is even higher 

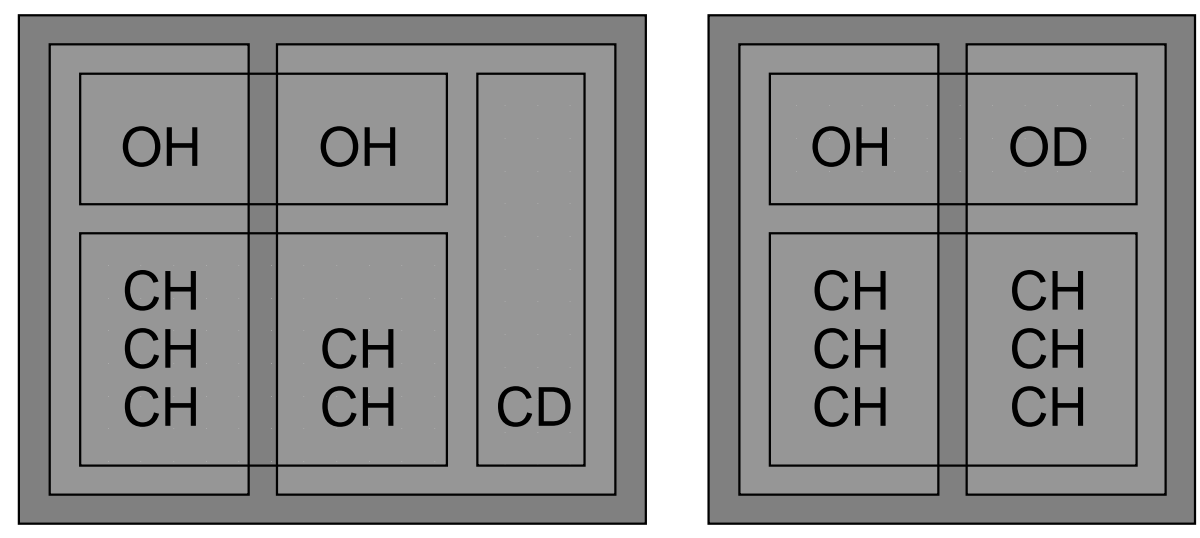

Fig. B3. Venn diagram for $\mathrm{CH}_{3} \mathrm{OH}+\mathrm{OH}$ reaction.

$\left(\mathrm{KIE}=5.233_{-1.410}^{+2.267}\right)$ than for the isotopologue with a deuterated methyl group. Together with the branching ratios of this reaction, these data provide sufficient information to derive the required abstraction probability ratios; $\eta_{\mathrm{CH}_{3} \mathrm{OH}+\mathrm{OH}}^{\mathrm{CD} \text {, }}$, $\eta_{\mathrm{CH}_{3} \mathrm{OH}+\mathrm{OH}}^{\mathrm{CH}}$, and $\eta_{\mathrm{CH}_{3} \mathrm{OH}+\mathrm{OH}}^{\mathrm{OH}}$. Using the same argument as in Sect. B1, we choose to set $\eta_{\mathrm{CH}_{3} \mathrm{OH}+\mathrm{OH}}^{\mathrm{CD} \mid \mathrm{CH}}$ equal to $1 / \eta_{\mathrm{CH}_{3} \mathrm{O}+\mathrm{O}}^{\mathrm{CH} \mid \mathrm{CD}}$ The second ratio can be calculated using the non-deuterated reaction branching ratios and is equal to 1.889 . We will calculate the third ratio at the end of this section. Similar to the derivation for methyl hydroperoxide in Sect. B2, we can immediately write the following expressions for Reaction (B7b) in Table A1:

$\mathrm{KIE}_{\mathrm{CH}_{2} \mathrm{DOH}+\mathrm{OH}} \cong \frac{1-X}{A+B}$,

with:

$$
\begin{gathered}
\frac{P\left(\mathrm{CH}_{2} \mathrm{DOH} \cap \mathrm{OH}\right)}{P\left(\mathrm{CH}_{3} \mathrm{OH} \cap \mathrm{OH}\right)+P\left(\mathrm{CH}_{3} \mathrm{OH} \cap \mathrm{CH}\right)} \\
\cong \frac{1}{1+\frac{P\left(\mathrm{CH}_{3} \mathrm{OH} \cap \mathrm{CH}\right)}{P\left(\mathrm{CH}_{3} \mathrm{OH} \cap \mathrm{OH}\right)}} \equiv A, \\
\frac{P\left(\mathrm{CH}_{2} \mathrm{DOH} \cap \mathrm{CH}\right)}{P\left(\mathrm{CH}_{3} \mathrm{OH} \cap \mathrm{OH}\right)+P\left(\mathrm{CH}_{3} \mathrm{OH} \cap \mathrm{CH}\right)} \\
\cong \frac{1}{1+\frac{P\left(\mathrm{CH}_{3} \mathrm{OH} \cap \mathrm{OH}\right)}{P\left(\mathrm{CH}_{3} \mathrm{OH} \cap \mathrm{CH}\right)}} \equiv B .
\end{gathered}
$$

and:

$$
\begin{aligned}
& P\left(\mathrm{CD} \mid \mathrm{CH}_{2} \mathrm{DOH}\right)= \\
& \frac{1 \eta_{\mathrm{CH}}^{\mathrm{CD} O \mathrm{OH}+\mathrm{OH}} \eta_{\mathrm{CH}}^{\mathrm{CH}} \mathrm{OH}+\mathrm{OH}}{2 \eta_{\mathrm{CH}_{3} \mathrm{OH}+\mathrm{OH}}^{\mathrm{CH}}+1 \eta_{\mathrm{CH}_{3} \mathrm{OH}+\mathrm{OH}}^{\mathrm{CD}} \eta_{\mathrm{CH}_{3} \mathrm{OH}+\mathrm{OH}}^{\mathrm{CH}}+1} \equiv X .
\end{aligned}
$$

The branching ratio for the reaction with the non-deuterated hydroxyl group becomes:

$$
\begin{aligned}
\alpha_{\mathrm{CH}_{2} \mathrm{DOH}+\mathrm{OH}}^{1} & \equiv P\left(\mathrm{OOH} \mid \mathrm{CH}_{2} \mathrm{DOH}\right) \\
& \cong P\left(\mathrm{OOH} \mid \mathrm{CH}_{3} \mathrm{OH}\right) \mathrm{KIE}_{\mathrm{CH}_{2} \mathrm{DOH}+\mathrm{OH}} .
\end{aligned}
$$

The IB ratios for the reaction with the deuterated methyl group become:

$$
\begin{aligned}
\alpha_{\mathrm{CH}_{2} \mathrm{DOH}+\mathrm{OH}}^{2 \mathrm{H}} & \equiv P\left(\mathrm{CH} \mid \mathrm{CH}_{2} \mathrm{DOH}\right) \\
& \cong \frac{2}{3} P\left(\mathrm{CH} \mid \mathrm{CH}_{3} \mathrm{OH}\right) \mathrm{KIE}_{\mathrm{CH}_{2} \mathrm{DOH}+\mathrm{OH}}
\end{aligned}
$$

and:

$$
\begin{aligned}
\alpha_{\mathrm{CH}_{2} \mathrm{DOH}+\mathrm{OH}}^{2 L} & \equiv P\left(\mathrm{CD} \mid \mathrm{CH}_{2} \mathrm{DOH}\right) \\
& \cong 1-P\left(\mathrm{OH} \mid \mathrm{CH}_{2} \mathrm{DOH}\right)-P\left(\mathrm{CH} \mid \mathrm{CH}_{2} \mathrm{DOH}\right) .
\end{aligned}
$$

The derivation of the expressions for Reaction (B7c) in Table A1 is also straightforward. First, we assume that:

$P\left(\mathrm{CH}_{3} \mathrm{OH} \mid \mathrm{CH}\right) \cong P\left(\mathrm{CH}_{3} \mathrm{OD} \mid \mathrm{CH}\right)$,

and:

$$
P\left(\mathrm{OD} \mid \mathrm{CH}_{3} \mathrm{OD}\right)=\frac{1}{3 \eta_{\mathrm{CH}_{3} \mathrm{OH}+\mathrm{OH}}^{\mathrm{CH} \mid \mathrm{OH}} \eta_{\mathrm{CH}_{3} \mathrm{OH}+\mathrm{OH}}^{\mathrm{OH} \mid \mathrm{OD}}+1} \equiv X .
$$

Together with the definition of the conditional probability, these two expressions can be used to calculate the inverse of the KIE from the following expression:

$$
\mathrm{KIE}_{\mathrm{CH}_{3} \mathrm{OD}+\mathrm{OH}}^{-1}=\frac{P\left(\mathrm{CH}_{3} \mathrm{OD} \cap \mathrm{OD}\right)+P\left(\mathrm{CH}_{3} \mathrm{OD} \cap \mathrm{CH}\right)}{P\left(\mathrm{CH}_{3} \mathrm{OH} \cap \mathrm{OH}\right)+P\left(\mathrm{CH}_{3} \mathrm{OH} \cap \mathrm{CH}\right)} .
$$

The final equation for the KIE becomes:

$\mathrm{KIE}_{\mathrm{CH}_{3} \mathrm{OD}+\mathrm{OH}} \cong \frac{1-X}{A}$,

with:

$$
A \equiv \frac{1}{1+\frac{P\left(\mathrm{CH}_{3} \mathrm{OH} \cap \mathrm{OH}\right)}{P\left(\mathrm{CH}_{3} \mathrm{OD} \cap \mathrm{CH}\right)}} .
$$


The IB ratios become:

$$
\begin{aligned}
\alpha_{\mathrm{CH}}^{1 \mathrm{OD}+\mathrm{OH}} & \equiv P\left(\mathrm{CH} \mid \mathrm{CH}_{3} \mathrm{OD}\right) \\
& \cong P\left(\mathrm{CH} \mid \mathrm{CH}_{3} \mathrm{OH}\right) \mathrm{KIE}_{\mathrm{CH}_{3} \mathrm{OD}+\mathrm{OH}},
\end{aligned}
$$

and:

$\alpha_{\mathrm{CH}_{3} \mathrm{OD}+\mathrm{OH}}^{1 \mathrm{~L}} \equiv 1-P\left(\mathrm{CH} \mid \mathrm{CH}_{3} \mathrm{OD}\right)$.

Similar to the fully explicit expression for $\mathrm{KIE}_{\mathrm{CH}_{3} \mathrm{D}+\mathrm{OH}}$ (Eq. 11) the explicit forms of Eqs. (B19) and (B29) can be derived:

$\mathrm{KIE}_{\mathrm{CH}_{2} \mathrm{DOH}+\mathrm{OH}} \cong \frac{3 \eta_{\mathrm{CH}_{3} \mathrm{OH}+\mathrm{OH}}^{\mathrm{CH} / \mathrm{OH}}+1}{2 \eta_{\mathrm{CH}_{3} \mathrm{OH}+\mathrm{OH}}^{\mathrm{CH} \mid \mathrm{OH}}+1 \eta_{\mathrm{CH}_{3} \mathrm{OH}+\mathrm{OH}}^{\mathrm{CD} \mid \mathrm{CH}} \eta_{\mathrm{CH}_{3} \mathrm{OH}+\mathrm{OH}}^{\mathrm{CH}}+1}$,

and:

$\mathrm{KIE}_{\mathrm{CH}_{2} \mathrm{OD}+\mathrm{OH}} \cong \frac{3 \eta_{\mathrm{CH} \mathrm{C}_{3} \mathrm{OH}+\mathrm{OH}}^{\mathrm{CH}} \eta_{\mathrm{CH} H_{3} \mathrm{OH}+\mathrm{OH}}^{\mathrm{OH} \mid \mathrm{OH}}+1 \eta_{\mathrm{CH} H_{3} \mathrm{OH}+\mathrm{OH}}^{\mathrm{OH} \mid \mathrm{OH}}}{3 \eta_{\mathrm{CH}_{3} \mathrm{OH}+\mathrm{OH}}^{\mathrm{CH}} \eta_{\mathrm{CH}_{3} \mathrm{OH}+\mathrm{OH}}^{\mathrm{OH}}+1}$.

The KIE's for the relevant reactions investigated by McCaul-

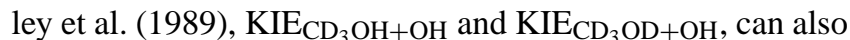
be expressed in a similar fashion. Finally, the last unknown abstraction probability ratio, $\eta_{\mathrm{CH}_{3} \mathrm{OH}+\mathrm{OH}}^{\mathrm{OH}}$, can be determined by fitting the algebraic values for the KIE's to the measured KIE's. An optimum result was found for very large values

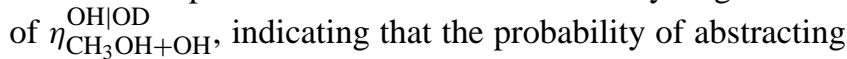
a deuteron from the hydroxyl site is very small, as was already noted by McCaulley et al. (1989). We therefore choose $\eta_{\mathrm{CH}_{3} \mathrm{OH}+\mathrm{OH}}^{\mathrm{OH}}$ equal to 1000 .

\section{B5 $\mathrm{CH}_{2} \mathrm{OH}+\mathrm{O}_{2}$ reaction}

The reaction of the hydroxy methyl radical $\left(\mathrm{CH}_{2} \mathrm{OH}\right)$ with $\mathrm{O}_{2}$ was studied by Grotheer et al. (1988), Nesbitt et al. (1988), and more recently by Olivella et al. (2001) and Schocker et al. (2007). A complete overview of the available measurements of the rate coefficient of this reaction can be found in Atkinson et al. (2006). The paper of Grotheer et al. (1988), states that, within the reported measurement uncertainty of $\pm 20 \%$, no significant isotope effect was observable for the $\mathrm{CH}_{2} \mathrm{OD}+\mathrm{O}_{2}$ reaction. The current consensus is that this observation together with the observed strong non-Arrhenius behavior as a function of temperature implies that this reaction proceeds via an intermediate $\mathrm{CH}_{2} \mathrm{OH} \cdot \mathrm{O}_{2}$ complex, can either dissociate back to its reactants or isomerize to $\mathrm{CH}_{2} \mathrm{O} \cdot \mathrm{HO}_{2}$. This radical then decomposes into $\mathrm{CH}_{2} \mathrm{O}$ and $\mathrm{HO}_{2}$. If we follow the proposed kinetics of this reaction, any deuterium atom present in the hydroxyl-group will be lost and any deuterium atom present in the methylgroup will end up in formaldehyde.

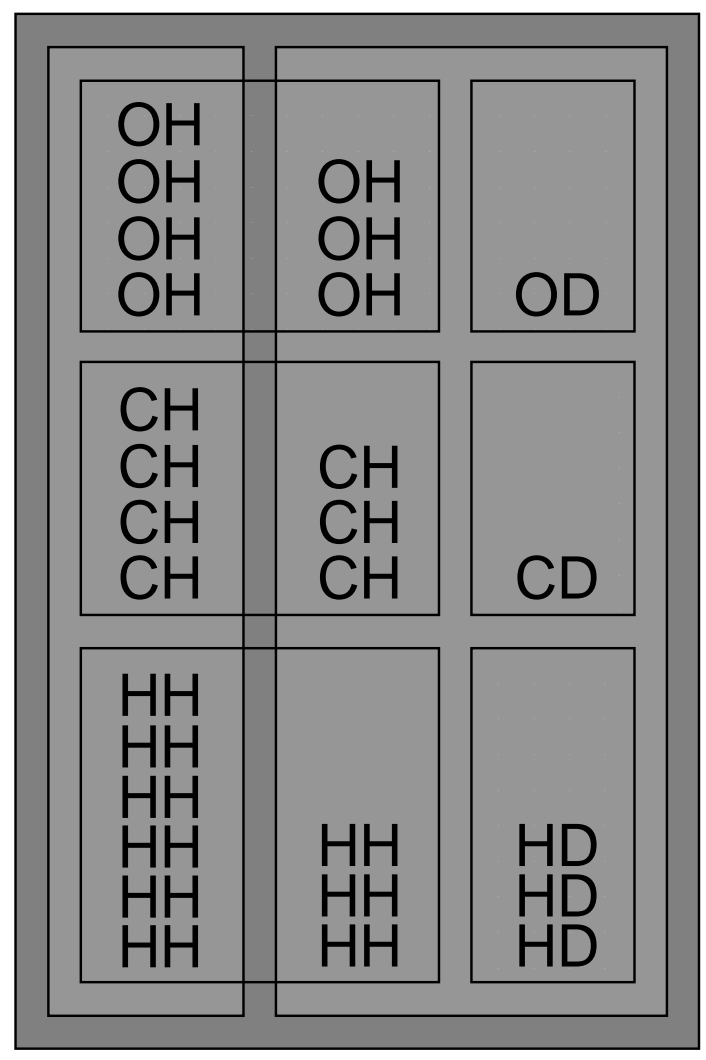

Fig. B4. Venn diagram for $\mathrm{CH}_{4}+\mathrm{O}\left({ }^{1} \mathrm{D}\right)$ reaction.

\section{B5.1 $\mathrm{CH}_{4}+\mathrm{O}\left({ }^{1} \mathrm{D}\right)$ reaction}

This reaction is very complicated to address because the oxidation of $\mathrm{CH}_{4}$ with $\mathrm{O}\left({ }^{1} \mathrm{D}\right)$ proceeds via three different reaction pathways with different products (Sander et al., 2006):

$$
\begin{aligned}
\mathrm{CH}_{4}+\mathrm{O}\left({ }^{1} \mathrm{D}\right) & \stackrel{0.750}{\longrightarrow} \mathrm{CH}_{3}+\mathrm{OH}, \\
& \stackrel{0.200}{\longrightarrow} \mathrm{CH}_{3} \mathrm{O}+\mathrm{H}, \\
& \stackrel{0.050}{\longrightarrow} \mathrm{CH}_{2} \mathrm{O}+\mathrm{H}_{2} .
\end{aligned}
$$

The different reaction probabilities for the non-deuterated and deuterated reactions are shown in Fig. B4.

In this figure, $\mathrm{OH}$ and $\mathrm{OD}$ denote the exchange of a hydrogen or deuterium atom with the impinging oxygen radical. $\mathrm{HH}$ or $\mathrm{HD}$ denotes for the exchange of $\mathrm{H}_{2}$ or $\mathrm{HD}$ with the incoming oxygen radical. Note that there are 6 possible combinations for the simultaneous abstraction of two hydrogen atoms. The three non-deuterated reaction branching ratios can be described in terms of conditional probabilities:

$P\left(\mathrm{CH} \mid \mathrm{CH}_{4}\right)=0.750$,

$P\left(\mathrm{OH} \mid \mathrm{CH}_{4}\right)=0.200$ 
and:

$P\left(\mathrm{HH} \mid \mathrm{CH}_{4}\right)=0.050$.

The independent bond approximation leads to the following expressions that relate the abstraction of hydrogen atoms from the deuterated molecules to the abstraction of hydrogen atoms from the non-deuterated molecules:

$P\left(\mathrm{CH}_{3} \mathrm{D} \cap \mathrm{CH}\right) \cong \frac{3}{4} P\left(\mathrm{CH}_{4} \cap \mathrm{CH}\right)$,

$P\left(\mathrm{CH}_{3} \mathrm{D} \cap \mathrm{OH}\right) \cong \frac{3}{4} P\left(\mathrm{CH}_{4} \cap \mathrm{OH}\right)$,

and:

$P\left(\mathrm{CH}_{3} \mathrm{D} \cap \mathrm{HH}\right) \cong \frac{3}{6} P\left(\mathrm{CH}_{4} \cap \mathrm{HH}\right)$.

Now we define the abstraction ratios for the deuterium atoms, derived directly from the conditional probabilities for the abstraction of one deuterium atom or the simultaneous abstraction of one hydrogen and one deuterium atom from $\mathrm{CH}_{3} \mathrm{D}$ :

$\frac{P\left(\mathrm{CD} \cap \mathrm{CH}_{3} \mathrm{D}\right)}{P\left(\mathrm{CH}_{3} \mathrm{D}\right)}=\frac{1 \eta_{\mathrm{CH}_{4}+\mathrm{O}\left({ }^{1} \mathrm{D}\right)}^{\mathrm{CD} \mid \mathrm{HD}}}{\tilde{\eta}} \equiv X$,

$\frac{P\left(\mathrm{OD} \cap \mathrm{CH}_{3} \mathrm{D}\right)}{P\left(\mathrm{CH}_{3} \mathrm{D}\right)}=\frac{1 \eta_{\mathrm{CH}_{4}+\mathrm{O}\left({ }^{1} \mathrm{D}\right)}^{\mathrm{OD}}}{\tilde{\eta}} \equiv Y$,

and:

$$
\frac{P\left(\mathrm{HD} \cap \mathrm{CH}_{3} \mathrm{D}\right)}{P\left(\mathrm{CH}_{3} \mathrm{D}\right)}=\frac{3}{\tilde{\eta}} \equiv Z,
$$

where:

$$
\begin{aligned}
\tilde{\eta} \equiv & 3 \eta_{\mathrm{CH}_{4}+\mathrm{O}\left({ }^{1} \mathrm{D}\right)}^{\mathrm{CH} \mid \mathrm{HD}}+1 \eta_{\mathrm{CH}_{4}+\mathrm{O}\left({ }^{1} \mathrm{D}\right)}^{\mathrm{CD} \mid \mathrm{HD}}+3 \eta_{\mathrm{CH}_{4}+\mathrm{O}\left({ }^{1} \mathrm{D}\right)}^{\mathrm{OH} \mid \mathrm{HD}} \\
& +1 \eta_{\mathrm{CH}_{4}+\mathrm{OD}\left({ }^{1} \mathrm{D}\right)}^{\mathrm{O} \mid}+3 \eta_{\mathrm{CH}_{4}+\mathrm{O}\left({ }^{1} \mathrm{D}\right)}^{\mathrm{HH}}+3 .
\end{aligned}
$$

All abstraction preference ratios are referred to the most improbable abstraction; The simultaneous abstraction of one hydrogen and one deuterium atom. The abstraction probability ratios in the expressions above are defined as follows:

$\eta_{\mathrm{CH}_{4}+\mathrm{O}\left({ }^{1} \mathrm{D}\right)}^{\mathrm{CH} \mid \mathrm{HD}}=\eta_{\mathrm{CH}_{4}+\mathrm{O}\left({ }^{1} \mathrm{D}\right)}^{\mathrm{CH})} \eta_{\mathrm{CH}_{4}+\mathrm{O}\left({ }^{1} \mathrm{D}\right)}^{\mathrm{HH})}$,

$\eta_{\mathrm{CH}_{4}+\mathrm{O}\left({ }^{1} \mathrm{D}\right)}^{\mathrm{CD} \mid \mathrm{HD}}=\eta_{\mathrm{CH}_{4}+\mathrm{O}\left({ }^{1} \mathrm{D}\right)}^{\mathrm{CD} \mid \mathrm{CH}} \eta_{\mathrm{CH}_{4}+\mathrm{O}\left({ }^{1} \mathrm{D}\right)}^{\mathrm{CH} \mid \mathrm{HH}} \eta_{\mathrm{CH}_{4}+\mathrm{O}\left({ }^{1} \mathrm{D}\right)}^{\mathrm{HH} \mid \mathrm{H}}$,

$\eta_{\mathrm{CH}_{4}+\mathrm{O}\left({ }^{1} \mathrm{D}\right)}^{\mathrm{OH} \mid \mathrm{HD}}=\eta_{\mathrm{CH}_{4}+\mathrm{O}\left({ }^{1} \mathrm{D}\right)}^{\mathrm{OH} \mid \mathrm{HH}} \eta_{\mathrm{CH}_{4}+\mathrm{O}\left({ }^{1} \mathrm{D}\right)}^{\mathrm{HH} / \mathrm{HD}}$, and:

$\eta_{\mathrm{CH}_{4}+\mathrm{O}\left({ }^{1} \mathrm{D}\right)}^{\mathrm{OD} / \mathrm{HD}}=\eta_{\mathrm{CH}_{4}+\mathrm{O}\left({ }^{1} \mathrm{D}\right)}^{\mathrm{OO} \mid \mathrm{OH}} \eta_{\mathrm{CH}_{4}+\mathrm{O}\left({ }^{1} \mathrm{D}\right)}^{\mathrm{OH} \mid \mathrm{HH}} \eta_{\mathrm{CH}_{4}+\mathrm{O}\left({ }^{1} \mathrm{D}\right)}^{\mathrm{HH} \mid \mathrm{HD}}$.

The abstraction probability ratios $\eta_{\mathrm{CH}_{4}+\mathrm{O}\left({ }^{1} \mathrm{D}\right)}^{\mathrm{CH} \mid \mathrm{HH}}$ and $\eta_{\mathrm{CH}_{4}+\mathrm{O}\left({ }^{1} \mathrm{D}\right)}^{\mathrm{OH}}$ can be derived from the branching ratios of the non-deuterated (Reaction (B3a) in Table A1). No data was available to derive the values for the remaining abstraction probability ratios. Therefore, we assumed $\eta_{\mathrm{CH}_{4}+\mathrm{O}\left({ }^{1} \mathrm{D}\right)}^{\mathrm{CD} / \mathrm{CH}}$ and $\eta_{\mathrm{CH}_{4}+\mathrm{O}\left({ }^{1} \mathrm{D}\right)}^{\mathrm{OD}}$ to be equal to $1 / \eta_{\mathrm{CH}_{4}+\mathrm{OH}}^{\mathrm{CH}}$. A bit arbitrarily, the last probability ratio was defined as:

$\eta_{\mathrm{CH}+\mathrm{CH}}^{\mathrm{CD}+\mathrm{O}\left({ }^{1} \mathrm{D}\right)}=\frac{2 \eta_{\mathrm{CH}}^{\mathrm{CH}+\mathrm{CD}\left({ }^{1} \mathrm{D}\right)}}{\eta_{\mathrm{CH}_{4}+\mathrm{O}\left({ }^{1} \mathrm{D}\right)}^{\mathrm{CH}}+1}$.

Due to the assumptions underlying the derivation above, the uncertainty in the actual values for the KIE and IB ratios is expected to be significant. Therefore, any results obtained from model calculations including the oxidation of $\mathrm{CH}_{4}$ by $\mathrm{O}\left({ }^{1} \mathrm{D}\right)$ in the hydrogen chemistry scheme can only be considered as indicative.

By writing the inverse of the KIE in a form similar to Eq. (B10) in Sect. B2, we can reduce the four numeratordenominator parts in the resulting expression to:

$A \equiv \frac{3}{4} \frac{1}{1+\frac{P\left(\mathrm{CH}_{4} \cap \mathrm{\cap H}\right)}{P\left(\mathrm{CH}_{4} \cap \mathrm{CH}\right)}+\frac{P\left(\mathrm{CH}_{4} \cap \mathrm{HH}\right)}{P\left(\mathrm{CH}_{4} \cap \mathrm{CH}\right)}}$,

$B \equiv \frac{3}{4} \frac{1}{\frac{P\left(\mathrm{CH}_{4} \cap \mathrm{CH}\right)}{P\left(\mathrm{CH}_{4} \cap \mathrm{OH}\right)}+1+\frac{P\left(\mathrm{CH}_{4} \cap \mathrm{HH}\right)}{P\left(\mathrm{CH}_{4} \cap \mathrm{OH}\right)}}$,

$C \equiv \frac{3}{6} \frac{1}{P\left(\mathrm{CH}_{4} \cap \mathrm{CH}\right)}+\frac{P\left(\mathrm{CH}_{4} \cap \mathrm{\cap OH}\right)}{P\left(\mathrm{CH}_{4} \cap \mathrm{HH}\right)}+1$.

and:

$D \equiv(X+Y+Z) \mathrm{KIE}_{\mathrm{CH}_{3} \mathrm{D}+\mathrm{O}\left({ }^{1} \mathrm{D}\right)}^{-1}$.

The expression for the KIE for this reaction thus becomes:

$\mathrm{KIE}_{\mathrm{CH}_{3} \mathrm{D}+\mathrm{O}\left({ }^{1} \mathrm{D}\right)} \cong \frac{1-X-Y-Z}{A+B+C}$.

Finally, we will derive the expressions for the IB ratios for this reaction. Using Eqs. (B41) to (B43) we can write the following expressions for the set of IB ratios that belong to the reactions for which the deuterium atom is preserved in the product molecules that are a precursor for HD:

$$
\begin{aligned}
\alpha_{\mathrm{CH}_{3} \mathrm{D}+\mathrm{O}\left({ }^{1} \mathrm{D}\right)}^{1 \mathrm{H}} & \equiv P\left(\mathrm{CH} \mid \mathrm{CH}_{3} \mathrm{D}\right) \\
& \cong \frac{3}{4} P\left(\mathrm{CH} \mid \mathrm{CH}_{4}\right) \mathrm{KIE}_{\mathrm{CH}_{3} \mathrm{D}+\mathrm{O}\left({ }^{1} \mathrm{D}\right)},
\end{aligned}
$$


Table C1. Considered bimolecular VOC oxidation reactions.

\begin{tabular}{|c|c|c|c|c|c|c|}
\hline Number & Reaction & & & {$\left[\mathrm{cm}^{3} \mathrm{molec}^{-1} \mathrm{~s}^{-1}\right]$} & $\begin{array}{l}\mathrm{E} / \mathrm{R} \\
{[\mathrm{K}]}\end{array}$ & KIE \\
\hline B15a & $\mathrm{C}_{5} \mathrm{H}_{8}+\mathrm{OH}$ & $\stackrel{2.000}{\longrightarrow}$ & $\mathrm{CH}_{2} \mathrm{O}$ & $2.70 \times 10^{-11}$ & -390 & \\
\hline $\mathrm{B} 15 \mathrm{~b}$ & $\mathrm{C}_{5} \mathrm{H}_{7} \mathrm{D}+\mathrm{OH}$ & $\frac{\alpha_{\mathrm{C}_{5} \mathrm{H}_{7} \mathrm{D}+\mathrm{OH}}^{\longrightarrow}}{\alpha_{\mathrm{C}_{5} \mathrm{H}_{7} \mathrm{D}+\mathrm{OH}}^{L}}$ & CHDO & & & 1 \\
\hline B16a & $\mathrm{PA}+\mathrm{NO}$ & $\rightarrow$ & $\begin{array}{l}\mathrm{CH}_{2} \mathrm{O} \\
\mathrm{CH}_{3} \mathrm{OO}\end{array}$ & $7.50 \times 10^{-12}$ & -290 & \\
\hline $\begin{array}{l}\text { B16b } \\
\text { B17a }\end{array}$ & $\begin{array}{l}\mathrm{DPA}+\mathrm{NO} \\
\mathrm{PA}+\mathrm{HO}_{2}\end{array}$ & $\stackrel{\alpha_{\mathrm{DPA}+\mathrm{NO}}}{\longrightarrow}$ & $\begin{array}{l}\mathrm{CH}_{2} \mathrm{DOO} \\
\mathrm{CH}_{3} \mathrm{OO}\end{array}$ & $5.20 \times 10^{-13}$ & -983 & 1 \\
\hline B17b & $\mathrm{DPA}+\mathrm{HO}_{2}$ & $\stackrel{\alpha_{\mathrm{DPA}+\mathrm{HO}_{2}}}{\longrightarrow}$ & $\mathrm{CH}_{2} \mathrm{DOO}$ & & & 1 \\
\hline
\end{tabular}

Table C2. Considered termolecular VOC oxidation reactions.

\begin{tabular}{|c|c|c|c|c|c|c|c|c|}
\hline Number & Reaction & & & {$\left[\begin{array}{c}\mathrm{k}_{0} \\
{\left[\mathrm{~cm}^{6} \mathrm{molec}^{-2} \mathrm{~s}^{-1}\right.}\end{array}\right.$} & 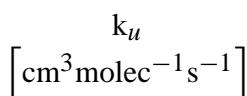 & $\mathrm{n}$ & $\mathrm{m}$ & KIE \\
\hline $\mathrm{T} 2 \mathrm{a}$ & $\mathrm{C}_{2} \mathrm{H}_{4}+\mathrm{OH}$ & $\rightarrow$ & $\mathrm{CH}_{2} \mathrm{O}$ & $7.0 \times 10^{-29}$ & $9.0 \times 10^{-12}$ & 3.1 & 0.0 & \multirow{3}{*}{1} \\
\hline \multirow[t]{2}{*}{$\mathrm{T} 2 \mathrm{~b}$} & \multirow{2}{*}{$\mathrm{C}_{2} \mathrm{H}_{3} \mathrm{D}+\mathrm{OH}$} & $\stackrel{\alpha_{\mathrm{C}_{2} \mathrm{H}_{3} \mathrm{D}+\mathrm{OH}}^{\mathrm{H}}}{\longrightarrow}$ & CHDO & & & & & \\
\hline & & $\stackrel{\alpha_{\mathrm{C}_{2} \mathrm{H}_{3} \mathrm{D}+\mathrm{OH}}^{L}}{\longrightarrow}$ & $\mathrm{CH}_{2} \mathrm{O}$ & & & & & \\
\hline T3a & $\mathrm{C}_{\mathrm{n}} \mathrm{H}_{2 \mathrm{n}}+\mathrm{OH}$ & $\stackrel{1.500}{\longrightarrow}$ & $\mathrm{CH}_{2} \mathrm{O}$ & $8.0 \times 10^{-27}$ & $3.0 \times 10^{-11}$ & 3.5 & 1.0 & \multirow{3}{*}{1} \\
\hline \multirow[t]{2}{*}{$\mathrm{T} 3 \mathrm{~b}$} & \multirow{2}{*}{$\mathrm{C}_{\mathrm{n}} \mathrm{H}_{2 \mathrm{n}-1} \mathrm{D}+\mathrm{OH}$} & $\stackrel{\alpha_{\mathrm{C}_{\mathrm{n}}}^{H} \mathrm{H}_{2 \mathrm{-1}} \mathrm{D}+\mathrm{OH}}{\longrightarrow}$ & $\mathrm{CHDO}$ & & & & & \\
\hline & & $\stackrel{\alpha_{\mathrm{C}_{\mathrm{n}}}^{L} \mathrm{n}_{-1} \mathrm{D}+\mathrm{OH}}{\longrightarrow}$ & $\mathrm{CH}_{2} \mathrm{O}$ & & & & & \\
\hline
\end{tabular}

$$
\begin{aligned}
\alpha_{\mathrm{CH}_{3} \mathrm{D}+\mathrm{O}\left({ }^{1} \mathrm{D}\right)}^{2 H} & \equiv P\left(\mathrm{OH} \mid \mathrm{CH}_{3} \mathrm{D}\right) \\
& \cong \frac{3}{4} P\left(\mathrm{OH} \mid \mathrm{CH}_{4}\right) \mathrm{KIE}_{\mathrm{CH}_{3} \mathrm{D}+\mathrm{O}\left({ }^{1} \mathrm{D}\right)},
\end{aligned}
$$

and:

$$
\begin{aligned}
\alpha_{\mathrm{CH}_{3} \mathrm{D}+\mathrm{O}\left({ }^{1} \mathrm{D}\right)}^{3 H} & \equiv P\left(\mathrm{HH} \mid \mathrm{CH}_{3} \mathrm{D}\right) \\
& \cong \frac{3}{6} P\left(\mathrm{HH} \mid \mathrm{CH}_{4}\right) \mathrm{KIE}_{\mathrm{CH}_{3} \mathrm{D}+\mathrm{O}\left({ }^{1} \mathrm{D}\right)} .
\end{aligned}
$$

The second set of IB ratios follows directly from Eqs. (B44) to (B46):

$\alpha_{\mathrm{CH}_{3} \mathrm{D}+\mathrm{O}\left({ }^{1} \mathrm{D}\right)}^{1 \mathrm{~L}} \equiv P\left(\mathrm{CD} \mid \mathrm{CH}_{3} \mathrm{D}\right)=X$,

$\alpha_{\mathrm{CH}_{3} \mathrm{D}+\mathrm{O}\left({ }^{1} \mathrm{D}\right)}^{2 L} \equiv P\left(\mathrm{OD} \mid \mathrm{CH}_{3} \mathrm{D}\right)=Y$,

and:

$\alpha_{\mathrm{CH}_{3} \mathrm{D}+\mathrm{O}\left({ }^{1} \mathrm{D}\right)}^{3 L} \equiv P\left(\mathrm{HD} \mid \mathrm{CH}_{3} \mathrm{D}\right)=Z$.

\section{B6 $\mathrm{CH}_{4}+\mathrm{Cl}$ reaction}

The reaction of methane with chlorine is characterized with an unusually large KIE; 1.459 at $298 \mathrm{~K}$ (Sander et al., 2006). Contrary to the reaction of methane with hydroxyl (see Sect. 2.1), the KIE $>4 / 3$ can not be expressed as a ratio of linear combinations of abstraction probability ratios if the abstraction probability of $\mathrm{H}$ is similar in both isotopologues. In this case, our independent bond approximation fails since the reactivity of the $\mathrm{C}-\mathrm{H}$ bonds is clearly affected by the presence of the C-D bond. As an ad hoc alternative to molecular kinetics calculations, we chose to introduce an extra parameter $f$ in the expression for the KIE for this reaction:

$$
\mathrm{KIE}_{\mathrm{CH}_{4}+\mathrm{Cl}}=\frac{4 \eta_{\mathrm{CH}_{4}+\mathrm{Cl}}^{\mathrm{CH} \mid \mathrm{CD}}}{3 \eta_{\mathrm{CH}_{4}+\mathrm{Cl}}^{\mathrm{CH}} f+1} .
$$

In this expression, $\eta_{\mathrm{CH}_{4}+\mathrm{Cl}}^{\mathrm{CH}}$ is set equal to $\eta_{\mathrm{CH}_{4}+\mathrm{OH}}^{\mathrm{CH}}$ and the value $f=0.855$ is chosen such that the resulting KIE equals the target value. The IB ratios can be calculated using:

$\alpha_{\mathrm{CH}_{3} \mathrm{D}+\mathrm{Cl}}^{\mathrm{H}} \equiv P\left(\mathrm{CH} \mid \mathrm{CH}_{3} \mathrm{D}\right) \cong \frac{3}{4} \mathrm{KIE}_{\mathrm{CH}_{3} \mathrm{D}+\mathrm{Cl}} f$,

(B65) 
and:

$\alpha_{\mathrm{CH}_{3} \mathrm{D}+\mathrm{Cl}}^{L} \equiv P\left(\mathrm{CD} \mid \mathrm{CH}_{3} \mathrm{D}\right) \cong 1-P\left(\mathrm{CH} \mid \mathrm{CH}_{3} \mathrm{D}\right)$.

\section{Appendix C}

\section{Overview of VOC oxidation reactions}

Please view Tables $\mathrm{C} 1$ and $\mathrm{C} 2$.

Acknowledgements. We would like to thank the Eurohydros consortium for their support for this work.

Edited by: J. Burkholder

\section{References}

Allan, W., Struthers, H., and Lowe, D.: Methane carbon isotope effects caused by atomic chlorine in the marine boundary layer: Global model results compared with Southern Hemisphere measurements, J. Geophys. Res., 112, D04306, doi:10.1029/2006JD007369, 2007.

Arsene, C., Bougiatioti, A., Kanakidou, M., Bonsang, B., and Mihalopoulos, N.: Tropospheric $\mathrm{OH}$ and $\mathrm{Cl}$ levels deduced from non-methane hydrocarbon measurements in a marine site, Atmos. Chem. Phys., 7, 4661-4673, 2007, http://www.atmos-chem-phys.net/7/4661/2007/.

Atkinson, R.: Kinetics and mechanisms of the gas-phase reactions of the $\mathrm{OH}$ radical with organic compounds under atmospheric conditions, Chem. Rev., 86, 69-201, 1986.

Atkinson, R.: A Structure-Activity Relationship for the Estimation of Rate Constants for the Gas-Phase Reactions of OH Radicals with Organic Compounds, Int. J. Chem. Kin., 19, 799-828, 1987.

Atkinson, R., Baulch, D. L., Cox, R. A., Crowley, J. N., Hampson, R. F., Hynes, R. G., Jenkin, M. E., Rossi, M. J., Troe, J., and IUPAC Subcommittee: Evaluated kinetic and photochemical data for atmospheric chemistry: Volume II - gas phase reactions of organic species, Atmos. Chem. Phys., 6, 3625-4055, 2006, http://www.atmos-chem-phys.net/6/3625/2006/.

Bacher, C., Tyndall, G. S., and Orlando, J. J.: The Atmospheric Chemistry of Glycolaldehyde, J. Atmos. Chem., 39, 171-189, 2001.

Barnes, I., Becker, K. H., and Ruppert, L.: FTIR product study of the self-reaction of $\beta$-hydroxyethyl peroxy radicals, Chem. Phys. Lett., 203, 295-301, 1993.

Brenninkmeijer, C. A. M., Janssen, C., Kaiser, J., Röckmann, T., Rhee, R. S., and Assonov, S. S.: Isotope effects in the chemistry of atmospheric trace components, Chem. Rev., 103, 5125-5161, 2003.

Cantrell, C. A., Shetter, R. E., McDaniel, A. H., Calvert, J. G., Davidson, J. A., Lowe, D. C., Tyler, S. C., Cicerone, R. J., and Greenberg, J. P.: Carbon kinetic isotope effect in the oxidation of methane by the hydroxyl radical, J. Geophys. Res., 95D, 455462,1990

Derwent, R. G., Jenkin, M. E., Saunders, S. M., and Pilling, M. J.: Photochemical ozone creation potentials for organic compounds in North West Europe calculated with a master chemical mechanism, Atmos. Environ., 32, 2429-2441, 1998.
Ehhalt, D. H.: Gas phase chemistry of the troposphere, in Global Aspects of Atmospheric Chemistry, in: Topics Phys. Chem., Vol. 6, edited by: Zellner, R., Springer-Verlag, New York, 21109, 1999.

Endresen, O., Sørgard, E., Sundet, J. K., Dalsøren, S. B., Isaksen, I. S. A., Berglen, T. F., and Gravir, G.: Emissions from international sea transport and environmental impact, J. Geophys Res., 108, 4560, doi:10.1029/2002JD002898, 2003.

Fan, J. and Zhang, R.: Atmospheric oxidation scheme of isoprene, Environ. Chem., 1, 140-149, 2004.

Feck, T., Grooß, J.-U., and Riese, M.: Sensitivity of Arctic ozone loss to stratospheric $\mathrm{H}_{2} \mathrm{O}$, Geophys. Res. Lett., 35, L01803, doi:10.1029/2007GL031334, 2008.

Feilberg, K. L., Johnson, M. S., and Nielsen, C. J.: Relative reaction rates of $\mathrm{HCHO}, \mathrm{HCDO}$, DCDO, $\mathrm{H}^{13} \mathrm{CHO}$, and $\mathrm{HCH}^{18} \mathrm{O}$ with $\mathrm{OH}, \mathrm{Cl}, \mathrm{Br}$, and $\mathrm{NO}_{3}$ radicals, J. Phys. Chem. A, 108, 73937398, 2004.

Feilberg, K. L., D’Anna, B., Johnson, M. S., and Nielsen, C. J.: Relative tropospheric photolysis rates of $\mathrm{HCHO}, \mathrm{H}^{13} \mathrm{CHO}$, $\mathrm{HCH}^{18} \mathrm{O}$, and DCDO measured at the European photoreactor facility (EUPHORE), J. Phys. Chem. A, 109, 8314-8319, 2005.

Feilberg, K. L., D’Anna, B., Johnson, M. S., and Nielsen, C. J.: Relative tropospheric photolysis rates of $\mathrm{HCHO}, \mathrm{H}^{13} \mathrm{CHO}$, $\mathrm{HCH}^{18} \mathrm{O}$, and DCDO measured at the European photoreactor facility (EUPHORE), J. Phys. Chem. A, 111, 992, 2007 a.

Feilberg, K. L., Johnson, M. S., Bacak, A., Röckmann, T., and Nielsen, C. J.: Relative tropospheric photolysis rates of HCHO and HCDO measured at the European photoreactor facility, J. Phys. Chem. A, 111, 9034-9036, 2007b.

Feria, L., Gonzalez, C., and Castro, M.: Ab initio study of the $\mathrm{CH}_{3} \mathrm{O}_{2}$ self-reaction in gas phase: Elucidation of the $\mathrm{CH}_{3} \mathrm{O}_{2}+\mathrm{CH}_{3} \mathrm{O}_{2} \rightarrow 2 \mathrm{CH}_{3} \mathrm{O}+\mathrm{O}_{2}$ pathway, Int. J. Quant. Chem. 99, 605-615, 2004.

Gerst, S. and Quay, P.: The deuterium content of atmospheric molecular hydrogen: Method and initial measurements, J. Geophys. Res., 105, 26433-26445, 2000.

Gerst, S. and Quay, P.: Deuterium component of the global molecular hydrogen cycle, J. Geophys. Res., 106, 5021-5031, 2001.

Gery, M. W., Whitten, G. Z., Killus, J. P., and Dodge, M. C.: A photochemical kinetics mechanism for urban and regional scale computer modeling, J. Geophys. Res., 94, 12925-12956, 1989.

Grotheer, H. H., Riekert, G., Walter, D., and Just, T.: NonArrhenius Behavior of the Reaction of Hydroxymethyl Radicals with Molecular Oxygen, J. Phys. Chem., 92, 4028-4030, 1988.

Hauglustaine, D. A. and Ehhalt, D. H.: A three-dimensional model of molecular hydrogen in the troposphere, J. Geophys. Res., 107(D17), 4330, doi:10.1029/2001JD001156, 2002.

Henon, E., Bohr, F., Chakir, A., and Brion, J.: Theoretical study of the methyl peroxy self-reaction: the intermediate structure, Chem. Phys. Lett., 264, 557-564, 1997.

Hess, W. P. and Tully, F. P.: Hydrogen-Atom Abstraction from Methanol by OH, J. Phys. Chem., 93, 1944-1947, 1989.

Houweling, S., Dentener, F., and Lelieveld, J.: The impact of nonmethane hydrocarbon compounds on tropospheric photochemistry, J. Geophys. Res., 103, 10673-10696, 1998.

Jenkin, M. E., Saunders, S. M., Wagner, V., and Pilling, M. J.: Protocol for the development of the Master Chemical Mechanism, MCM v3 (Part B): tropospheric degradation of aromatic volatile organic compounds, Atmos. Chem. Phys., 3, 181-193, 2003, 
http://www.atmos-chem-phys.net/3/181/2003/.

Jiménez, E., Gilles, M. K., and Ravishankara, A. R.: Kinetics of the reactions of the hydroxyl radical with $\mathrm{CH}_{3} \mathrm{OH}$ and $\mathrm{C}_{2} \mathrm{H}_{5} \mathrm{OH}$ between 235 and 360 K, J. Photochem. Photobiol. A: Chemistry, 157, 237-245, 2003.

JMA and NASA-WFF: World Ozone and Ultraviolet Radiation Data Centre (WOUDC) [Data], http://www.woudc.org, Retrieved: 2 December 2008.

Karunanandan, R., Hö1lscher, D., Dillon, T. J., Horowitz, A., and Crowley, J. N.: Reaction of $\mathrm{HO}$ with Glycolaldehyde, $\mathrm{HOCH}_{2} \mathrm{CHO}$ : Rate Coefficients (240-362 K) and Mechanism, J. Phys. Chem. A, 111, 897-908, 2007.

Krol, M., Houweling, S., Bregman, B., van den Broek, M., Segers, A., van Velthoven, P., Peters, W., Dentener, F., and Bergamaschi, P.: The two-way nested global chemistry-transport zoom model TM5: algorithm and applications, Atmos. Chem. Phys., 5, 417432, 2005, http://www.atmos-chem-phys.net/5/417/2005/.

Kwok, E. and Atkinson, R.: Estimation of hydroxyl radical reaction rate constants for gas-phase organic compounds using a structure-reactivity relationship: An update, Atmos. Environ., 29, 1685-1695, 1995.

Lathière, J., Hauglustaine, D. A., De Noblet-Ducoudré, N., Krinner, G., and Folberth, G. A.: Past and future changes in biogenic volatile organic compound emissions simulated with a global dynamic vegetation model, Geophys. Res. Lett., 32, L20818, doi:10.1029/2005GL024164, 2005.

Lathière, J., Hauglustaine, D. A., Friend, A. D., De NobletDucoudré, N., Viovy, N., and Folberth, G. A.: Impact of climate variability and land use changes on global biogenic volatile organic compound emissions, Atmos. Chem. Phys., 6, 2129-2146, 2006, http://www.atmos-chem-phys.net/6/2129/2006/.

Levin, I., Bergamaschi P., Dörr, H., and Trapp, D.: Stable isotopic signature of methane from major sources in Germany, Chemosphere, 26, 161-177, 1993.

Lightfoot, P. D., Cox, R. A., Crowley, J. N., Destriau, M., Hayman, G. D., Jenkin, M. E., K., M. G., and Zabel, F.: Organic peroxy radicals: kinetics, spectroscopy and tropospheric chemistry, Atmos. Environ., 26A, 1805-1961, 1992.

Mar, K. A., McCarthy, M. C., Connell, P., and Boering, K. A.: Modeling the photochemical origins of the extreme deuterium enrichment in stratospheric $\mathrm{H}_{2}$, J. Geophys. Res., 112, D19302, doi:10.1029/2006JD007403, 2007.

McCaulley, J. A., Kelly, N., Golde, M. F., and Kaufman, F.: Kinetic Studies of the Reactions of $\mathrm{F}$ and $\mathrm{OH}$ with $\mathrm{CH}_{3} \mathrm{OH}$, J. Phys. Chem., 93, 1014-1018, 1989.

McGillen, M. R., Crosier, J. C., Percival, C. J., Sanchez-Rayna, G., and Shallcross, D. E.: Can topological indices be used to predict gas-phase rate coefficients of importance to tropospheric chemistry? Reactions of alkenes with $\mathrm{OH}, \mathrm{NO}_{3}$ and $\mathrm{O}_{3}$, Chemosphere, 65, 2035-2044, 2006a.

McGillen, M. R., Percival, C. J., Raventos-Duran, T., SanchezRayna, G., and Shallcross, D. E.: Can topological indices be used to predict gas-phase rate coefficients of importance to tropospheric chemistry? Free radical abstraction reactions of alkanes, Atmos. Environ., 40, 2488-2500, 2006 b.

McGillen, M. R., Percival, C. J., Pieterse, G., Watson, L. A., and Shallcross, D. E.: Predicting arene rate coefficients with respect to hydroxyl and other free radicals in the gas-phase: a simple and effective method using a single topological descriptor, Atmos. Chem. Phys., 7, 3559-3569, 2007,

http://www.atmos-chem-phys.net/7/3559/2007/.

Minato, T., Yamabe, S., Fujimoto, H., and Fukui, K.: A molecularorbital calculation of chemically-interacting systems. Interaction between two radicals. Self-reaction of peroxyl radicals, Bull. Chem. Soc. Jpn., 51, 682-689, 1978.

Nesbitt, F. L., Payne, W. A., and Stief, L. J.: Temperature dependence for the absolute rate constant for the reaction $\mathrm{CH}_{2} \mathrm{OH}+\mathrm{O}_{2}$ $\rightarrow \mathrm{HO}_{2}+\mathrm{H}_{2} \mathrm{CO}$ from $215 \mathrm{~K}$ to $300 \mathrm{~K}$, J. Phys. Chem., 92, 4030 4032, 1988.

Niki, H., Maker, P. D., M., S. C., and Breitenbach, L. P.: An FTIR study of mechanisms for the $\mathrm{HO}$ radical initiated oxidation of $\mathrm{C}_{2} \mathrm{H}_{4}$ in the presence of NO: Detection of glycolaldehyde, Chem. Phys. Lett., 80, 499-503, 1981.

Nilsson, E. J. K., Johnson, M. S., Taketani, F., Matsumi, Y., Hurley, M. D., and Wallington, T. J.: Atmospheric deuterium fractionation: $\mathrm{HCHO}$ and $\mathrm{HCDO}$ yields in the $\mathrm{CH}_{2} \mathrm{DO}+\mathrm{O}_{2}$ reaction, Atmos. Chem. Phys., 7, 5873-5881, 2007, http://www.atmos-chem-phys.net/7/5873/2007/.

Novelli, P. C., Lang, P. M., Masarie, K. A., Hurst, D. F., Myers, R., and Elkins, J. W.: Molecular hydrogen in the troposphere: Global distribution and budget, J. Geophys. Res., 104, 30427 30444, 1999.

Olivella, S., Bofill, J. M., and Soé, A.: Ab Initio Calculations on the Mechanism of the Oxidation of the Hydroxymethyl Radical by Molecular Oxygen in the Gas Phase: A Significant Reaction for Environmental Science, Chem. Eur. J., 7, 3377-3386, 2001.

Orlando, J. J., Tyndall, G. S., Bilde, M., Ferronato, C., Wallington, T. J., Vereecken, L., and Peeters, J.: Laboratory and Theoretical Study of the Oxy Radicals in the $\mathrm{OH}$ - and Cl-Initiated Oxidation of Ethene, J. Phys. Chem. A, 102, 8116-8123, 1998.

Pöschl, U., Kuhlmann, R. v., Poisson, N., and Crutzen, P. J.: Development and intercomparison of condensed isoprene oxidation mechanisms for global atmospheric modeling, J. Atmos. Chem., 37, 29-52, 2000.

Press, W., Teukolsky, S., Vetterling, W., and Flannery, B.: Numerical Recipes in C, Cambridge University Press, 2nd Edn., 1992.

Price, H., Jaeglé, L., Rice, A., Quay, P., Novelli, P. C., and Gammon, R.: Global budget of molecular hydrogen and its deuterium content: Constraints from ground station, cruise, and aircraft observations, J. Geophys. Res., 112, D22108, doi:10.1029/2006JD008152, 2007.

Rahn, T., Kitchen, N., and Eiler, J. M.: D/H ratios of atmospheric $\mathrm{H}_{2}$ in urban air: Results using new methods for analysis of nanomolar $\mathrm{H}_{2}$ samples, Geochim. Cosmochim. Acta, 66, 2475-2481, 2002b.

Rahn, T., Eiler, J. M., Boering, K. A., Wennberg, P. O., McCarthy, M. C., Tyler, S., Schauffler, S., Donnelly, S., and Atlas, E.: Extreme deuterium enrichment in stratospheric hydrogen and the global atmospheric budget of $\mathrm{H}_{2}$, Nature, 424, 918-921, 2003.

Ravishankara, A. R.: Kinetics of radical reactions in the atmospheric oxidation of $\mathrm{CH}_{4}$, Ann. Rev. Phys. Chem., 39, 367-394, 1988.

Rhee, T. S., Mak, J. E., Brenninkmeijer, C. A. M., and Röckmann, T.: Continuous-flow isotope analysis of the $\mathrm{D} / \mathrm{H}$ ratio in atmospheric hydrogen, Rap. Commun. Mass Spectrom., 18, 299-306, 2004.

Rhee, T. S., Brenninkmeijer, C. A. M., Brass, M., and Bruhl, C.: 
Isotopic composition of $\mathrm{H}_{2}$ from $\mathrm{CH}_{4}$ oxidation in the stratosphere and the troposphere, J. Geophys. Res., 111, D23303, doi:10.1029/2005JD006760, 2006a.

Rhee, T. S., Brenninkmeijer, C. A. M., and Röckmann, T.: The overwhelming role of soils in the global atmospheric hydrogen cycle, Atmos. Chem. Phys., 6, 1611-1625, 2006b,

http://www.atmos-chem-phys.net/6/1611/2006/.

Rhee, T. S., Brenninkmeijer, C. A. M., and Röckmann, T.: Hydrogen isotope fractionation in the photolysis of formaldehyde, Atmos. Chem. Phys., 8, 1353-1366, 2008, http://www.atmos-chem-phys.net/8/1353/2008/.

Rice, A. L. and Quay, P. D.: Isotopic analysis of atmospheric formaldehyde by gas chromatography isotope ratio mass spectrometry, Anal. Chem., 78, 6320-6326, 2006.

Röckmann, T., Rhee, T. S., and Engel, A.: Heavy hydrogen in the stratosphere, Atmos. Chem. Phys., 3, 2015-2023, 2003, http://www.atmos-chem-phys.net/3/2015/2003/.

Sander, S. P., Finlayson-Pitts, B. J., Friedl, R. R., Golden, D. M., Huie, R. E., Keller-Rudek, H., Kolb, C. E., Kurylo, M. J., Molina, M. J., Moortgat, G. K., Orkin, V. L., R., R. A., and Wine, P. H.: Chemical Kinetics and Photochemical Data for Use in Atmospheric Studies, Evaluation Number 15, Tech. rep., JPL Publication 06-2, Jet Propulsion Laboratory, Pasadena, 2006.

Sanderson, M. G., Collins, W. J., Derwent, R. G., and Johnson, C. E.: Simulation of global hydrogen levels using a lagrangian threedimensional model, J. Atmos. Chem., 46, 15-28, 2003.

Saueressig, G., Bergamaschi, P., Crowley, J. N., Fischer, H., and Harris, G. W.: D/H kinetic isotope effect in the reaction $\mathrm{CH}_{4}+$ Cl, Geophys. Res. Lett., 23, 3619-3622, 1996.

Saueressig, G., Crowley, J. N., Bergamaschi, P., Brühl, C., Brenninkmeijer, C. A. M., and Fischer, H.: ${ }^{13} \mathrm{C}$ and $\mathrm{D}$ kinetic isotope effects in the reactions of $\mathrm{CH}_{4}$ with $\mathrm{O}^{1} \mathrm{D}$ and $\mathrm{OH}$ : New laboratory measurements and their implications for the isotopic composition of stratospheric methane, J. Geophys. Res., 106, $23127-$ 23138, 2001.

Saunders, S. M., Jenkin, M. E., Derwent, R. G., and Pilling, M. J.: World wide Web site of a master chemical mechanism (MCM) for use in tropospheric chemistry models, Atmos. Environ., 31, 1249, http://mcm.leeds.ac.uk/MCM/, 1997.
Saunders, S. M., Jenkin, M. E., Derwent, R. G., and Pilling, M. J.: Protocol for the development of the Master Chemical Mechanism, MCM v3 (Part A): tropospheric degradation of nonaromatic volatile organic compounds, Atmos. Chem. Phys., 3 , 161-180, 2003, http://www.atmos-chem-phys.net/3/161/2003/.

Schocker, A., Uetake, M., Kanno, N., Koshi, M., and Tonokura, K.: Kinetics and Rate Constants of the Reaction $\mathrm{CH}_{2} \mathrm{OH}+\mathrm{O}_{2} \rightarrow \mathrm{CH}_{2} \mathrm{O}+\mathrm{HO}_{2}$ in the Temperature Range of 236600 K, J. Phys. Chem. A, 111, 6622-6627, 2007.

Schultz, M. G., Diehl, T., Brasseur, G. P., and Zittel, W.: Air pollution and climate-forcing impacts of a global hydrogen economy, Science, 302, 624-627, 2003.

Tromp, T. K., Shia, R.-L., Allen, M., Eiler, J. M., and Yung, Y. L.: Potential Environmental Impact of a Hydrogen Economy on the Stratosphere, Science, 300, 1740-1742, 2003.

Tyndall, G. S., Wallington, T. J., and Ball, J. C.: FTIR Product Study of the Reactions $\mathrm{CH}_{3} \mathrm{O}_{2}+\mathrm{CH}_{3} \mathrm{O}_{2}$ and $\mathrm{CH}_{3} \mathrm{O}_{2}+\mathrm{O}_{3}$, J. Phys. Chem. A, 102, 2547-2254, 1998.

Tyndall, G. S., Cox, R. A., Granier, C., Lesclaux, R., Moortgat, G. K., Pilling, M. J., Ravishankara, A. R., and Wallington, T. J.: Atmospheric chemistry of small organic peroxy radicals, J. Geophys. Res., 106, 12157-12182, 2001.

van der Werf, G. R., Randerson, J. T., Collatz, G. J., and Giglio, L.: Carbon emissions from fires in tropical and subtropical ecosystems, Global Change Biol., 9, 547-562, 2003.

Venn, J.: On the Diagrammatic and Mechanical Representation of Propositions and Reasonings, Dublin Philosophical Magazine J. Sci., 9, 1-18, 1880.

Warwick, N. J., Bekki, S., Nisbet, E. G., and Pyle, J. A.: Impact of a hydrogen economy on the stratosphere and troposphere studied in a 2D model, Geophys. Res. Lett., 31, L05107, doi:10.1029/2003GL019224, 2004.

Weaver, J., Meagher, J., R., S., and Heicklen, J.: The oxidation of acetyl radicals, J. Photochem., 4, 341-360, 1975.

Zahn, A., Franz, P., Bechtel, C., Grooß, J.-U., and Röckmann, T.: Modelling the budget of middle atmospheric water vapour isotopes, Atmos. Chem. Phys., 6, 2073-2090, 2006, http://www.atmos-chem-phys.net/6/2073/2006/. 